\title{
1 Cellulose and potential reinforcement
}

There are numerous examples where animals or plants synthesize extracellular highperformance skeletal biocomposites consisting of a matrix reinforced by fibrous biopolymers. Cellulose, the most abundant polymer on Earth, is a classic example of these reinforcing elements. It is a ubiquitous structural polymer that confers its mechanical properties to higher plant cells. Natural cellulose-based materials have been used by our society as engineering materials for thousands of years and this continues today given the worldwide huge markets and industries for forest products, paper, textiles ... A closer look to this material reveals a hierarchical structure design which is the source of its functionality, flexibility and high strength/weight performance.

\subsection{Polysaccharides}

Polysaccharides form part of the group of molecules known as carbohydrates and have been proposed as the first biopolymers to have formed on Earth (Tolstoguzov, 2004). This term was applied originally to compounds with the general formula $\mathrm{C}_{\mathrm{x}}\left(\mathrm{H}_{2} \mathrm{O}\right)_{\mathrm{y}}$ but now it is also used to describe a variety of derivatives including nitrogenand sulfur-containing compounds. Carbohydrates were once thought to represent "hydrated carbon". However, the arrangement of atoms in carbohydrates has little to do with water molecules. They are classified on the basis of their main monosaccharide components and the sequences and linkages between them, as well as the anomeric configuration of linkages, the ring size (furanose or pyranose), the absolute configuration (D- or L-) and any other substituents present.

Three common "single" sugars or monosaccharides, viz. glucose, galactose and fructose, share the same molecular formula $\mathrm{C}_{6} \mathrm{H}_{12} \mathrm{O}_{6}$, and because of their six carbon atoms, each is a hexose (Figure 1.1). Although all three share the same molecular formula, the arrangement of atoms differs in each case and these substances, which have different structural formulas, are known as structural isomers.

Two monosaccharides can be linked together to form a "double" sugar or disaccharide. Three common disaccharides can be found: sucrose (common table sugar,

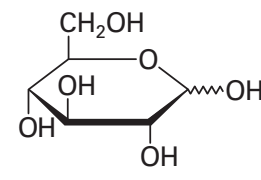

(a) glucose

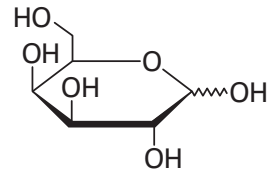

(b) galactose

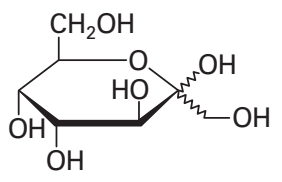

(c) fructose

Fig. 1.1: Chemical structure of (a) glucose, (b) galactose and (c) fructose. 
consisting of glucose + fructose), lactose (major sugar in milk, consisting of glucose + galactose) and maltose (product of starch digestion, consisting of two glucose units). Although the process of linking of two monomers is rather complex, the end result in each case is the loss of a hydrogen atom from one of the monosaccharides and a hydroxyl group from the other. The resulting linkage between the sugars is called a glycosidic bond. All sugars are highly soluble in water because of their many hydroxyl groups and although not as concentrated a fuel as fats, they are the most important source of energy for many cells. Further linkages of disaccharides lead to polysaccharides.

Certain structural characteristics, such as chain conformation and intermolecular associations, will influence the physico-chemical properties of polysaccharides. The most stable arrangement of atoms in a polysaccharide will be that which satisfies both the intra- and inter-molecular forces. Regular ordered polysaccharides are in general capable of assuming only a limited number of conformations due to severe steric restrictions on the freedom of rotation of sugar units about the interunit glycosidic bonds. There is also a clear correlation between allowed conformations and linkage structure. The structural non-starch polysaccharides, such as cellulose and xylan, have preferred orientations that automatically support extended conformations. Storage polysaccharides, such as the chains in amylopectin, tend to adopt wide helical conformations. The degree of stiffness and regularity of polysaccharide chains is likely to affect the rate and extent of their fermentation. Pentose sugars, such as arabinose and xylose, can adopt one of two specific conformations, furanose rings (often formed by arabinose) that can oscillate and are more flexible, and pyranose rings (usually formed by xylose and glucose) which are less flexible.

Carbohydrates, especially those containing large numbers of hydroxyl groups, are often thought of as being hydrophilic but they are also capable of generating apolar surfaces depending on the monomer ring conformation, the epimeric structure, and the stereochemistry of the glycosidic linkages. Apolarity has been demonstrated for dextrin, $\alpha$-(l-4)-linked glucans, while dextran $\alpha$-(l-6)-glucans, and cellulose, $\beta$-(l-4)-glucans, are much less hydrophobic (in solution) and unable to project an apolar surface. Hydrophobicity will also be affected by the degree of polysaccharide hydration, particularly the amount of intra-molecular hydrogen bonding. Hydrophobicity will affect their availability for fermentation in the gut, and their binding to bile acids.

Polysaccharides are more hydrophobic if they have a greater number of internal hydrogen bonds, and as their hydrophobicity increases there is less direct interaction with water. Carbohydrates contain hydroxyl (alcohol) groups that preferentially interact with two water molecules each if they are not in interaction with other hydroxyl groups on the molecule. Interaction with hydroxyl groups on the same or neighboring residues will necessarily reduce the polysaccharide's hydration status. $\beta$-linkages to the 3- and 4- positions in mannose or glucose homopolymers allow strong inflexible inter-residue hydrogen bonding, so reducing polymer hydration, and giving rise 
to rigid inflexible structural polysaccharides, whereas $\alpha$-linkages to the 2-, 3- and 4positions in mannose or glucose homopolymers give rise to greater aqueous hydration and more flexible linkages (Almond, 2005).

\subsection{Chemical structure of the cellulose macromolecule}

Though cellulose has been used for centuries in highly diverse applications, its chemical composition, structure and morphology remained very long ignored. Advances in the state of knowledge on the molecular structure of cellulose is intimately linked to the evolution of characterization techniques such as X-ray diffraction, electron microscopy, ${ }^{13} \mathrm{C}$ solid state nuclear magnetic resonance (NMR) spectroscopy, neutron scattering ...

The early work of Braconnot concerning the acid hydrolysis of the substance constituting plant cell walls goes back to the early XIX century (Braconnot, 1819). However, it was Anselme Payen who established that the fibrous component of all plant cells has a unique chemical structure (Payen, 1838) and first used the term "cellulose" in 1838. He discovered that when plant tissue, cotton linters, root tips, pit and ovules from the flowers of trees are purified with an acid-ammonia treatment, followed by an extraction in water, a constant fibrous material was formed. It required 75 more years for the basic cellulose formula to be established by Willstätter and Zechmeister (1913).

This fibrous, tough, and water-insoluble substance is found in the protective cell walls of plants, particularly in stalks, stems, trunks and all woody portions of plant tissues. More generally, lower (fresh-water and marine algae) and higher (bushes and trees) plants, bacteria, fungi, and animals (for example, tunicates-cellulose from the mantle of tunicates is named tunicin) as well as some amoebas are well-known natural sources of cellulose. Cellulose is often said to be the most abundant polymer on Earth. It is certainly one of the most important structural elements in plants and other living species serving to maintain their structure. Each of these living species, from tree to bacteria, produces cellulose day-by-day, e.g. a tree produces about $10 \mathrm{~g}$ of cellulose per day and the total production of cellulose all over the world is estimated to be $1.3 \cdot 10^{10}$ tons per year (Sandermann, 1973). Other sources indicate that the global annual production of cellulose is estimated at $1.5 \cdot 10^{12}$ tons (Klemm et al., 2005).

The paper and cardboard industries are the largest consumers of cellulose. Only $2 \%$ of the cellulose used (3.2 million tons in 2003) is used to produce fibers, films of regenerated cellulose and for the synthesis of cellulose esters or ethers. Technological development, especially in the field of molecular biology, in these areas offers new opportunities. Some animals, particularly ruminants and termites, can digest cellulose with the help of symbiotic microorganisms. Cellulose is not digestible by humans, and is often referred to as "dietary fiber" or "roughage". To date, several reviews have been published on cellulose research, structure and applications (Gardner and 
Blackwell, 1974; Preston, 1975; Sarko, 1987; Okamura, 1991; Hon, 1994; O’Sullivan, 1997; Zugenmaier, 2001; Kovalenko, 2010).

Cellulose structure has been under investigation since the early days of polymer science. It was shown (Irvine and Hirst, 1923; Freudenberg and Braun, 1928) that 2,3,6 trimethyl glucose was the sole quantitative product resulting from methylation and hydrolysis of cellulose. This work evidenced that in cellulose the carbon atoms 2, 3 and 6 carried free hydroxyls available for reaction. The basic chemical structure of cellulose is presented in Figure 1.2. It is composed of $\beta$-1,4-linked D-glucopyranose rings. The adjacent monomer units are arranged so that glucosidic oxygens point in opposite directions and the repeating unit of the polymer chain of cellulose is composed of two $\beta$-D-glucopyranose rings rotated with respect to each other to form a so-called cellobiose unit (Figure 1.2). The numbering system for carbon atoms in anhydroglucose unit of cellulose is also indicated in Figure 1.2. The $\mathrm{C}-\mathrm{O}-\mathrm{C}$ bond angle between two $\beta$-D-glucopyranose rings is $\sim 116^{\circ}$ (Tarchevsky and Marchenko, 1991). Nowadays, the conformation of the glucopyranose ring is well established because numerous crystallographic investigations of D-glucose and cellobiose (Chu and Jeffrey, 1968) and other physico-chemical studies (Marszalek et al., 1998) provided evidence that the ring adopts a chair conformation designated ${ }^{4} \mathrm{C} 1$ (in cellulose esters or ethers, the ring retains this conformation (Kovalenko, 2010)). As a result of its equatorialequatorial glycosidic linkage, the cellulose chains have their units positioned so that their adjacent rings can form hydrogen bonds between the ring oxygen atom of one glycosil unit and the hydrogen atom of the C-3 hydroxyl group of the preceding ring. These hydrogen bonds hinder the free rotation of the rings along their linking glycoside bonds resulting in the stiffening of the chain.

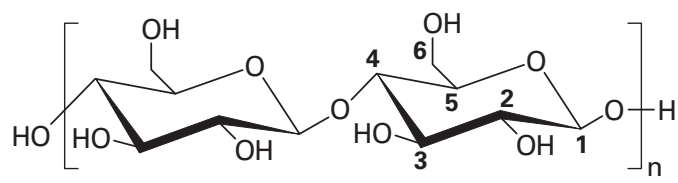

Fig. 1.2: Basic chemical structure of cellulose and numbering system for carbon atoms in anhydroglucose unit of cellulose.

These cellobiose units are covalently linked to form an extended, insoluble, straight chain of linear homopolymer consisting of between 2,000-27,000 residues. The degree of polymerization (DP) of native cellulose depends on the source and cellulose chains are supposed to consist of approximately 10,000 glucopyranose units in wood cellulose and 15,000 in native cotton cellulose (Sjoström, 1981). There is some evidence for a lower DP in primary cell walls compared with secondary cell walls. Valonia presents a DP around 26,500. Given a glucose unit as $0.515 \mathrm{~nm}$ (5.15 $\mathrm{\AA}$ ) long, 
for DP values ranging from 2,000 to 27,000, the cellulose molecules may have average lengths ranging between 1 and $14 \mu \mathrm{m}$ by considering stretched chains.

However, chain lengths of such large, insoluble molecules are rather difficult to measure and the DP of native cellulose is not well established. The combination of procedures required to isolate, purify and solubilize cellulose generally causes enzymatic and mechanical degradation during analysis resulting in chains scission. The values of DP obtained are therefore minimal and depend on the method used to determine it. For the same reasons the distribution of chain lengths of cellulose is not well established. Nonetheless, some authors suggest that the molecular mass distribution should be homogeneous for a given source of cellulose (Marx-Figini, 1964).

One of the most specific characteristic of cellulose is that each of its monomers bears three hydroxyl groups. These hydroxyl groups and their hydrogen bonding ability play a major role in directing crystalline packing and in governing important physical properties of these highly cohesive materials. The two chain ends are chemically different. One end has a D-glucopyranose unit in which the anomeric carbon atom is involved in a glycosidic linkage and has a free secondary alcohol function on the C4. The other end has a D-glucopyranose unit in which the anomeric carbon atom is free. This cyclic hemiacetal function is in an equilibrium in which a small proportion is an aldehyde which gives rise to reducing properties at this end of the chain so that the cellulose chain has a chemical polarity. This end is called reductive because it has the ability to reduce $\mathrm{Cu}^{2+}$ ions into $\mathrm{Cu}^{+}$ions in a Fehling's solution. This gives native cellulose a certain chemical polarity. Determination of the relative orientation of cellulose chains in the three-dimensional structure has been and remains one of the major problems in the study of cellulose.

\subsection{Biosynthesis of cellulose}

The biosynthesis of cellulose is a very complex phenomenon that reflects two linked processes. The first one is the formation of $\beta-1,4-\mathrm{D}$-glucopyranose chains by the polymerization of glucose, and the other one is the organization of fibrillar supramolecular architecture which leads to the formation of elongated crystalline structures. The latter, called microfibrils, correspond to a collection of highly oriented cellulose chains. In vascular plants, cellulose is the constituent that ensures the protection and support of plant cells, and it is directly synthesized in the cell wall at the plasma membrane. The polymerization of glucose is provided by an enzyme system whose main family is named cellulose synthase (CS). This enzyme family cannot function without the presence of another class of enzymes called SUSY (sucrose synthase). The SUSY ensures a continuous supply of UDP-glucose (uridine diphosphate-glucose) required for the operation.

In the presence of CS, the UDP-glucose unit initiates the polymerization process by loss of the UDP unit and dimerization of glucose. Many studies have been under- 
taken in order to create in vitro polymerization of glucose. The biosynthesis of cellulose using bacteria, including Acetobacter xylinium was conducted in 1985 and led to the synthesis of fibrils in vitro by CS solubilized in the presence of Acetobacter xylinium (Lin et al., 1985). Within the plant cell, the model of Delmer and Amor proposed in 1995 (Delmer and Amor, 1995) represents the protein complex through the cytoplasmic membrane (Figure 1.3). This model describes the growth of glycosidic chains and the catalytic role of the main enzymes.

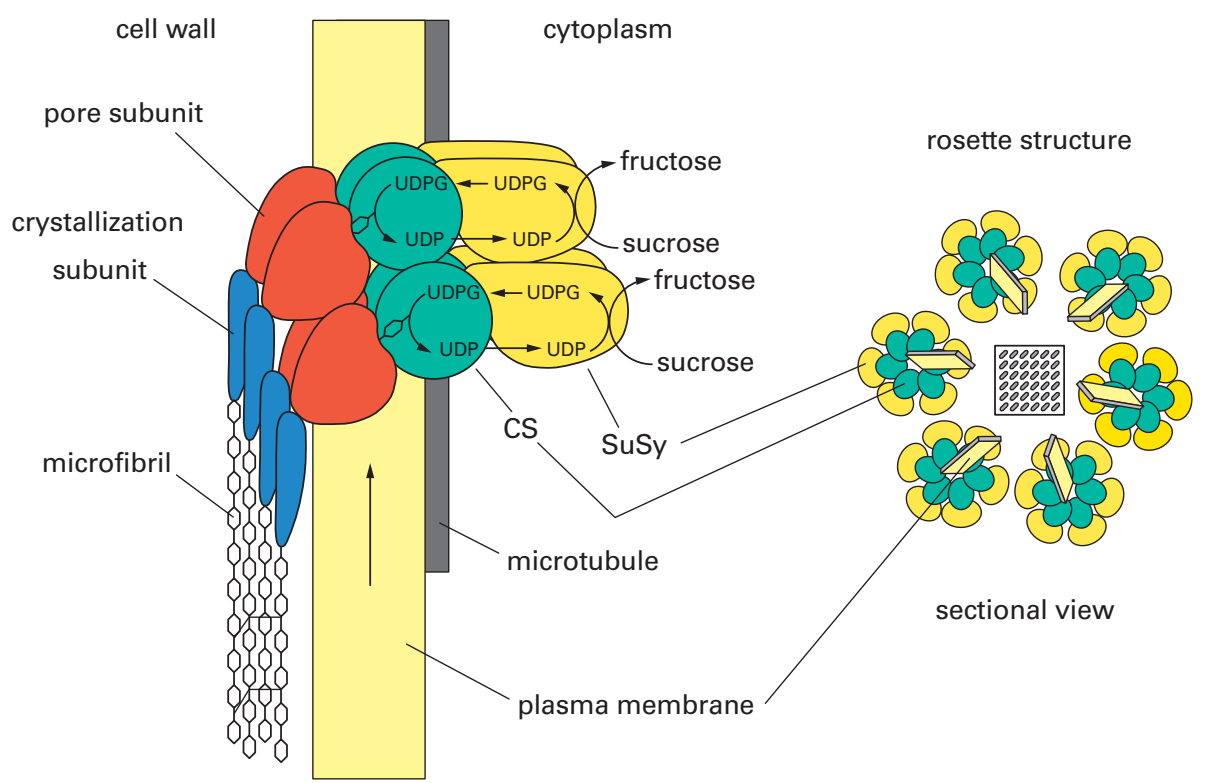

Fig. 1.3: Enzymatic system of polymerization of glucose across the plasma membrane: hypothetical model of a cellulose synthase complex in the plasma membrane (adapted from Delmer and Amor, 1995).

SUSY hydrolyzes sucrose to fructose by creating a UDP-glucose unit and it is within the CS that polymerization occurs. This observation shows that microfibril bundles grow in a single plane of symmetry. A sectional view shows that these planes are organized as rosettes (Saxena and Brown, 2000a). This simplified view does not report the entire phenomenon. The CS is not a single enzyme but contains several that are classified into major families of cellulose synthase (Saxena and Brown, 2000b). Indeed, there is probably no biochemical reaction in plants that is both so important and so poorly understood at the molecular level.

At the biopolymer chains supramolecular architecture level, electron microscopy studies conducted in 1976 showed that cellulose as a biopolymer displays an arrangement known as microfibrils (Frey-Wyssling, 1976). Glucose chains aggregate together 
by hydrogen bonds to form the metastable form of cellulose usually called cellulose I (see Section 1.4) (Cousins and Brown, 1995). The process of formation of the microfibrils may be provided by four steps from the polymerization to the supramolecular arrangement of the chains. The first step consists in the enzymatic polymerization of glucose monomers (Figure 1.4, step 0). The chains are subsequently linked by van der Waals forces to form micro-sheets (Figure 1.4, step 1). The micro-sheets join together by hydrogen bonds to form microcrystals (Figure 1.4, step 2). Finally, several microcrystals combine to give the microfibrils (Figure 1.4, step 3) (Cousins and Brown, 1995).

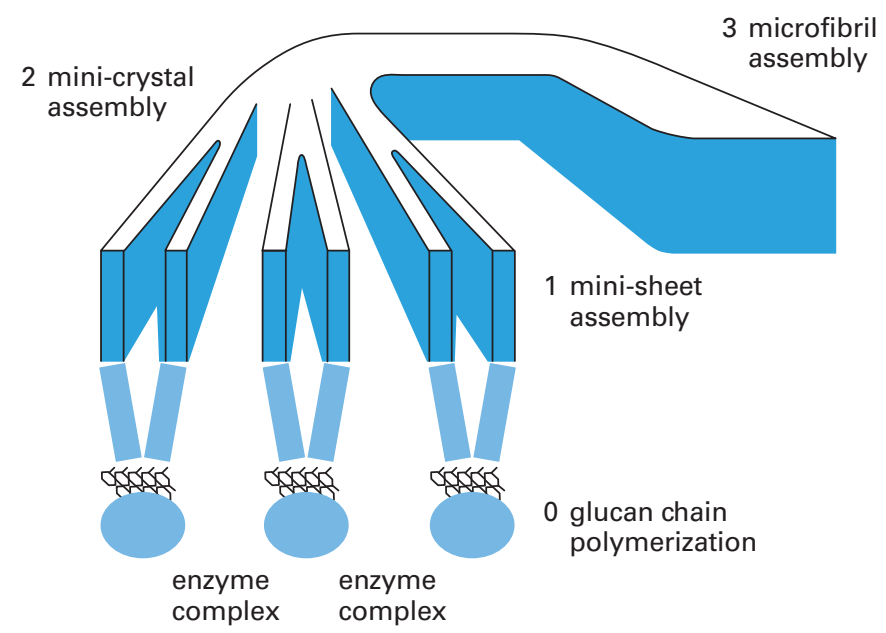

Fig. 1.4: A proposed model for the stages of microfibril formation: (0) glucose monomers are polymerized enzymatically from catalytic sites in the enzyme complex subunits to form glucan chains, (1) the glucan chains associate via van der Waals forces to form mini-sheets, (2) mini-sheets associate and hydrogen bond to form mini- or microcrystals, (3) several microcrystals then associate to form a crystalline microfibril (Cousins and Brown, 1995).

The polymerization process is achieved by successive addition of two glucose units, which allows to say that the polymerization unit is not glucose but cellobiose. At the supramolecular level, the formation of microfibrils explains the parallel growth of polymeric chains. This metastable architecture is the one found in the majority of lignocellulosic plants, called cellulose I. However, during in vitro synthesis, the cellulose chains arrange themselves in the crystalline form of cellulose II thermodynamically more stable (see Section 1.4). The designation cellulose I is related to the fact that the crystalline structure of cellulose is not unique, which leads to raise the issue of polymorphism of cellulose. 


\subsection{Polymorphism of cellulose}

The ribbon-like character observed for cellulosic macromolecules allows adjacent cellulose chains to fit closely together in an ordered crystalline region. The free hydroxyl groups present in the cellulose macromolecule are likely to be involved in a number of intra and inter molecular hydrogen bonds, which may give rise to various ordered crystalline arrangements. In the cellulose biosynthesis, the polymerization of glucopyranose residues and the formation of crystalline domains are interrelated.

Cellulose has several polymorphs. The polymorphism is most typical of crystals of organic compounds whose molecules contain groups capable of hydrogen bonding (Bernstein, 2002). The repeating unit of cellulose, or cellobiose, includes six hydroxyl groups and three oxygen atoms. Therefore, many possibilities of various hydrogen bonding systems result from the presence of six hydrogen bond donors and nine hydrogen bond acceptors. Because of different mutual arrangements of the glucopyranose rings and possibility of conformational changes of the hydroxymethyl groups, cellulose chains can exhibit different crystal packings (Kovalenko, 2010). As a result, cellulose exists in several crystal modifications, differing in unit cell dimensions and, possibly, in chain polarity. The possible transitions between the different cellulose polymorphs are presented schematically in Figure 1.5.

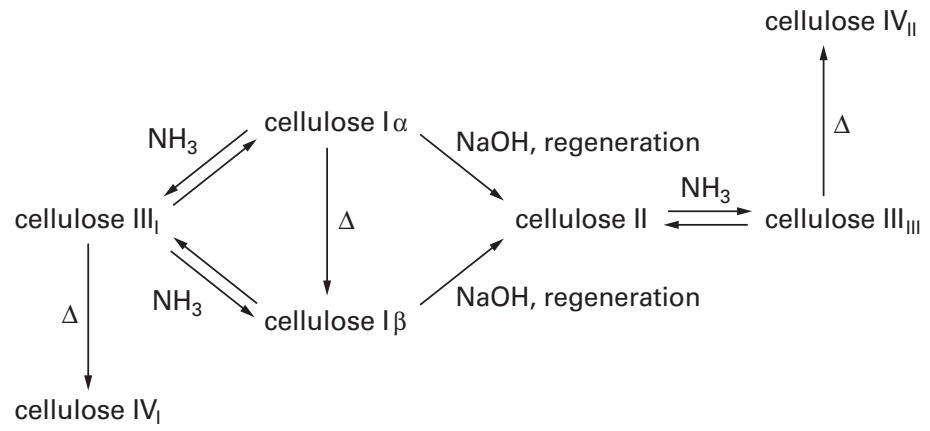

Fig. 1.5: Interconversions of cellulose polymorphs.

\subsubsection{Cellulose I}

In nature, cellulose is found in the crystalline form of cellulose I (native cellulose). As a first approximation, the structure of native cellulose determined by X-ray diffraction was described as a monoclinic cell containing two cellulose chains (Gardner and Blackwell, 1974). The first assignment of the peaks obtained by ${ }^{13} \mathrm{C}$ cross polarized magic angle spinning (CP/MAS) NMR was performed by Earl and VanderHart (1981). Atalla and VanderHart (1984) have shown by NMR spectroscopic studies that 
native cellulose is composed of more than one crystalline form and is a mixture consisting of two polymorphs, viz. cellulose I $\alpha$ and I $\beta$. Differences were reported in the resonances of the $\mathrm{C} 1$ atoms. A singlet and a doublet appeared around $106 \mathrm{ppm}$ for cellulose $\mathrm{I} \alpha$ and $\mathrm{I} \beta$, respectively. Initial ambiguity in the interpretation of crystallographic data for native cellulose may be largely attributed to the co-existence of these two polymorphs. These two crystalline forms have the same conformation of the heavy atom skeleton, but differ in their hydrogen bonding patterns. The I $\alpha$ form represents a triclinic phase with one-chain-per-unit cell, while the $\mathrm{I} \beta$ form represents a monoclinic phase with two-chains-per-unit cell. This description has been numerically simulated (Vietor et al., 2000). Nishiyama et al. (2003a) have confirmed and refined the crystal structures of both $\mathrm{I} \alpha$ and $\mathrm{I} \beta$ phases by the determination of the various network systems of hydrogen bonds. The experiments were conducted using jointly X-ray and neutron diffraction on hydrogenated and deuterated oriented fibers. The neutron diffraction experiments have allowed, among other things, replacing the hydroxyl hydrogen atoms by deuterium atoms, to determine the geometry of intraand interchain hydrogen bonding for both phases.

The ratio of the two allomorphs I $\alpha$ and I $\beta$ differs greatly depending on the species. The I $\alpha$ phase is mainly found in celluloses produced by primitive organisms, such as algae or bacteria, while cellulose I $\beta$ lies mainly in the cellulose produced by higher plants (cotton, wood, ...) and animals, such as in the envelope of marine animals (Belton et al., 1989). In wood pulp, for example, the I $\beta$ phase prevails with a proportion of about $64 \%$. Almost pure I $\alpha$ cellulose can be obtained from bacteria (e.g., Acetobacter xylinum) or from the cell walls of fresh-water algae Glaucosystis nostochinearum (Nishiyama et al., 2003b; Saxena and Brown, 2005; Witter et al., 2006). Polymorph I $\beta$ is the major part of cellulose found in cotton, wood, and ramie and of tunicin from Halocynthia roretzi (Saxena and Brown, 2005; Nishiyama et al., 2002; Nishiyama et al., 2008). Tunicin possesses only the I $\beta$ form but no pure sample of $I \alpha$ has been found in nature. Bacterial cellulose has the highest content $(70 \%)$ of polymorph I $\alpha$.

The content of polymorphs I $\alpha$ and I $\beta$ in cellulose can be changed under external actions. Indeed, the polymorph $\mathrm{I} \alpha$ can be converted (not completely, however) into the more stable $\mathrm{I} \beta$ phase by annealing at $260^{\circ} \mathrm{C}$ to $280^{\circ} \mathrm{C}$ in various media, such as organic solvents or helium (Debzi et al., 1991), hydrolysis (Atalla et al., 1985) or passage through cellulose III. For example, annealing at $260^{\circ} \mathrm{C}$ in a 0.1 sodium hydroxide solution converts most of the I $\alpha$ to the $\mathrm{I} \beta$ form. The dynamics of the transformation of polymorph I $\alpha$ into I $\beta$ under heating of cellulose I $\alpha$ in an inert atmosphere was investigated. Powder X-ray diffraction and two-dimensional Fourier transform infrared correlation spectroscopic studies showed that a high-temperature intermediate was formed around $200^{\circ} \mathrm{C}$ (Wada et al., 2003; Watanabe et al., 2007). The existence of both polymorphs in cellulose may affect the reactivity of native cellulose as I $\alpha$ is metastable and thus more reactive than $\mathrm{I} \beta$. 


\subsubsection{Cellulose II}

Native cellulose can be converted irreversibly into the thermodynamically more favorable cellulose II polymorph by swelling native cellulose I (metastable form) in concentrated sodium hydroxide aqueous solutions (17 to 20\% wt/vol) and removal of the swelling agent (this alkali treatment is named mercerization process after its inventor Mercer in 1844). Mercerization is used to activate the polymer prior to the production of technical cellulose ether. The mercerization of cellulose leads only to its swelling, but not to dissolution. The insertion of chemical species induces the structural change and the passage from a structure with parallel cellulosic chains to a configuration with anti-parallel chains.

Cellulose II can also be prepared by regeneration, which is the solubilization of cellulose I in a solvent followed by precipitation by dilution into an aqueous medium. This is the typical process for the technical spinning of man-made cellulose fibers. There are several industrial processes for the regeneration of cellulose, viz. fortisan (not used nowadays), viscose, copper ammonium, and N-methylmorpholine $\mathrm{N}$-oxide (NMMO) processes. All these processes involve the dissolution of cellulose followed by the formation of regenerated cellulose fibers.

It was found that regeneration gives a higher level of conversion of cellulose I to cellulose II (Kolpak and Blackwell, 1976). The crystalline structure of cellulose II, determined by Kolpak et al. (1978) and Stipanovic and Sarko (1976), was studied by neutron diffraction to confirm that contrary to cellulose I, the arrangement is antiparallel chains (Lagan et al., 1999) which allows the establishment of a larger number of intermolecular hydrogen bonds than the native form. The transition from cellulose I to cellulose II is irreversible, which suggest that cellulose II is thermodynamically more stable than cellulose I. Cellulose II, like cellulose I $\beta$, has the monoclinic unit cell. The different arrangement of the chains (parallel in cellulose I $\beta$ and antiparallel in cellulose II) is the most substantial difference between these two polymorphs. Even though the unit cells of cellulose II obtained by the two routes (mercerized and regenerated cellulose) resemble each other closely, small differences have been reported (Wellard, 1954).

Cellulose II is formed naturally by a mutant strain of Gluconacetobacter xylinum (Kuga et al., 1993) and occurs in the alga Halicystis (Sisson, 1938). They were both very useful to provide an insight into the crystalline structure of cellulose II.

\subsubsection{Cellulose III}

Treatment with liquid ammonia or with certain organic amines, such as ethylene diamine (EDA), followed by washing with alcohol allows the preparation of cellulose III either from cellulose I (which leads to the form cellulose $\mathrm{III}_{\mathrm{I}}$ ) or from cellulose II (which leads to the form III II). A hexagonal unit cell is reported for cellulose III and it 
has been found that the polarity of the resultant cellulose chains resembles that of the starting material. The lattice dimensions of cellulose III $_{\mathrm{I}}$ and cellulose $\mathrm{III}_{\mathrm{II}}$ are similar.

These transformations are reversible, suggesting that the chain orientation is similar to the one of the starting material. However, at the crystalline level, an extensive decrystallization and fragmentation of the cellulose crystals were observed during the conversion of cellulose I to cellulose III $_{\mathrm{I}}$ (Sarko et al., 1976; Roche and Chanzy, 1981; Reis et al., 1991). During the reverse transition, i.e. conversion back to cellulose I, partial recrystallization takes place but the distortion and fragmentation of the crystals are irreversible and restoration of the damage done to the morphological surface is incomplete. It was shown by ${ }^{13} \mathrm{C}$ NMR that the transformation of cellulose I to cellulose III I polymorph induces a significant reduction of the lateral dimensions of the crystallites (Sarko et al., 1976). At the same time, the cellulose chains show conformational changes arising from the primary hydroxyl groups.

\subsubsection{Cellulose IV}

Cellulose III treated at high temperature in glycerol is transformed into cellulose IV. Again two types exist, viz. cellulose $\mathrm{IV}_{\mathrm{I}}$ and $\mathrm{IV}_{\mathrm{II}}$ obtained from cellulose $\mathrm{III}_{\mathrm{I}}$ and $\mathrm{III}_{\mathrm{II}}$, respectively. The conversions are never totally complete, which explains the difficulties in the production of good quality X-ray diffraction patterns (Buléon and Chanzy, 1980). It is generally accepted that cellulose IV $_{I}$ is a disordered form of cellulose $I$. This could explain the reported occurrence of this form in the native state in some plants (primary walls of cotton and some fungi) as determined by X-ray diffraction (Chanzy et al., 1978; Chanzy et al., 1979). It has been confirmed by studies based on X-ray diffraction and ${ }^{13} \mathrm{C}$ solid state CP-MAS NMR experiments (Wada et al., 2004).

\subsection{Cellulose microfibrils}

As shown previously, the presence of many hydroxyl groups along the cellulose chain results in the formation of a network of intra- and intermolecular hydrogen bonds. In addition, a network of van der Waals connections is established between the chains layers (French et al., 1993). These two link networks allow the establishment of ordered crystalline structures. Intramolecular hydrogen bonds occur primarily between the hydrogen borne by the $\mathrm{OH}$ group of the $\mathrm{C} 3$ carbon cycle and oxygen from the adjacent ring (05) (see Figure 1.6). There may also be an interaction between the hydrogen borne by the primary OH group of the C6 carbon and oxygen from the carbon 2 hydroxyl of the adjacent ring. The intermolecular bonds occur between the hydrogen of the HO-6 primary hydroxyl and oxygen in position 03 in a cycle of a neighboring unit. 


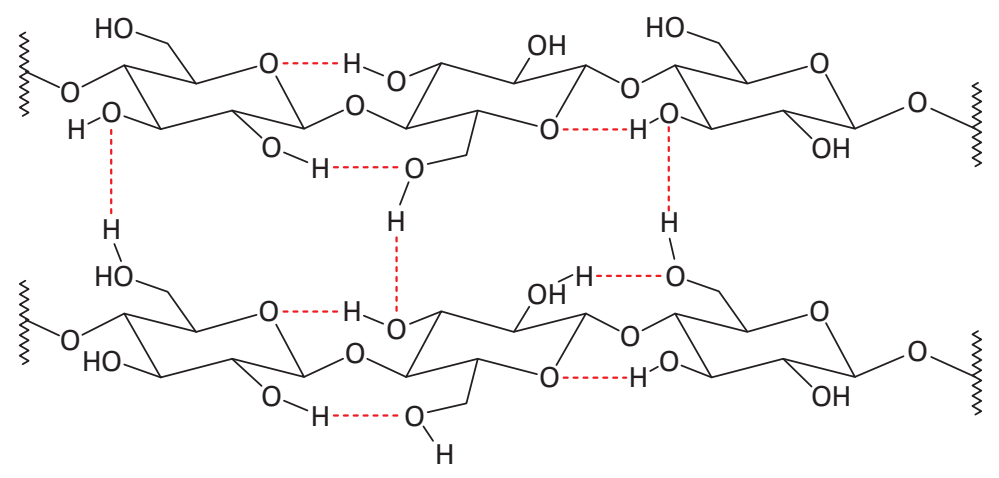

Fig. 1.6: Schematic representation of intra- and intermolecular hydrogen bonds in cellulose.

This ordered molecular arrangement of cellulosic chains parallel to each other is the basis of a crystal structure called microfibrils. The hierarchy of structure and supramolecular organization of cellulose are schematized in Figure 1.7.

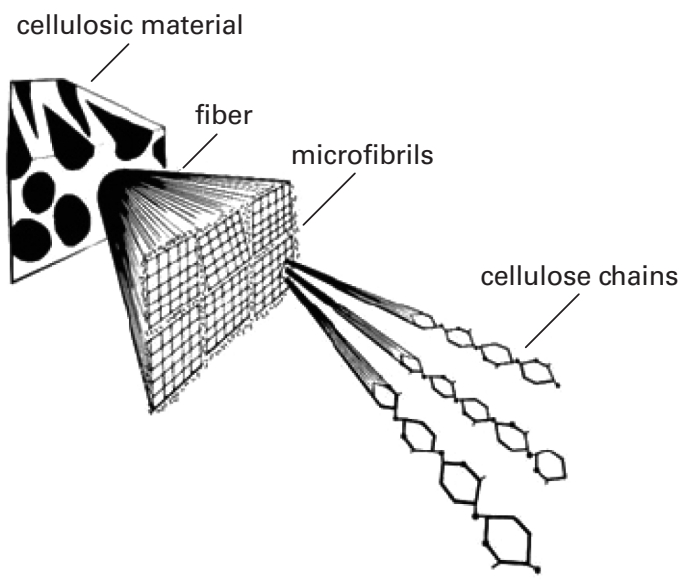

Fig. 1.7: Schematic representation of the hierarchical structure of a lignocellulosic fiber (after Marchessault and Sundararajan, 1983).

The microfibrillar nature of cellulose was established from electron microscopy observations (Frey-Wyssling et al., 1948, Preston and Cronshaw, 1958). To describe the arrangement of the chains within the microfibrils, several models have been proposed. They can be grouped into two categories: the models with stretched chains (Frey-Wyssling, 1954, Hess et al., 1957) and the models with folded chains (Dolmetsch and Dolmetsch, 1962, St John Manley, 1964; Marx-Figini and Schulz, 1966). The latter have been abandoned in favor of a crystal with stretched chains thanks to DP meas- 
urements performed on microtomed ramie fibers (Muggli et al., 1969; Mühlethaler, 1969) and small angle X-ray diffraction experiments conducted by Bonard in 1966 (Bonard, 1966). The stretched chains model was validated by studying the mechanical properties of cellulose fibrils and the DP as a function of the length of the sample (Mark et al., 1969). It clearly indicated that the cellulose chains exist in an extended form in the crystal. More recent works on the chain polarity of cellulose microfibrils showed that the chains are parallel to the main axis of the microfibrils. This orientation has been evidenced by experiments highlighting the unidirectional nature of the degradation of microcrystalline cellulose from Valonia under the action of exocellulases (Chanzy and Henrissat, 1985).

Microfibrils have widths, lengths, shapes and crystallinities that may vary depending on the origin of cellulose as shown by transmission electron microscopy observations (Chanzy, 1990). However, they are always significantly longer than wide. The width of the microfibrils can vary from 2-3 nm for the cell walls of primary tissues of some plants to $60 \mathrm{~nm}$ for certain algae. The section of microfibrils from Valonia is assumed to be square (Sassi and Chanzy, 1995) while that of tunicates is rather lozenge-shaped and becomes edged off after hydrolysis (Revol et al., 1992, Van Daele et al., 1992; Sugiyama et al., 1992). The schematic morphological characteristics of microfibrils of different origins are shown in Figure 1.8.

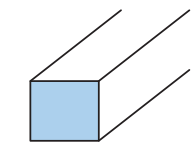

15-25 nm alga (Valonia)

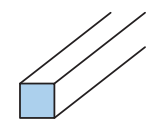

5-10 nm secondary wall (coton)

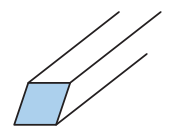

10-15 nm tunicate (Halocynthia papillosa)

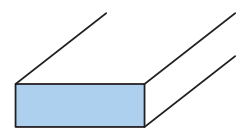

$60-5 \mathrm{~nm}$ alga (Micrasterias)

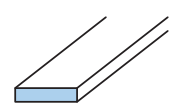

8-9 nm bacterial (Acetobacter xylinum)

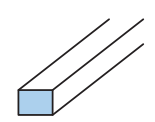

1.5-3 nm primary wall (parenchyma)

Fig. 1.8: Microfibril morphology depending on the origin of cellulose and order of magnitude of the widths.

For a long time, studies carried out at the sub-microscopic scale emphasized the discontinuous character of microfibrils. Experimental evidence was provided by wide angle (Fink et al., 1987) and small angle X-ray diffraction (Grigoriew and Chmielewski, 1998), ${ }^{13} \mathrm{C}$ CP/MAS solid state NMR experiments (Earl and VanderHart, 1981), and tensile tests performed on cellulose fibers (Ishikawa et al., 1997). Confinement of 
microfibrils during their biosynthesis generates twists distributed along the chain. In these zones, the crystalline arrangement is destroyed. The periodic nature of this distribution of disordered or amorphous regions has been shown for ramie microfibrils by small angle neutron diffraction (Nishiyama et al., 2003a) with a periodicity of about $150 \mathrm{~nm}$ corresponding to the sizes estimated by diffraction of hydrolyzed microfibrils.

The exact organization of crystallites in the microfibril has not been up to now fully elucidated (number, spatial arrangement) but the microfibrillar model of cellulose considers a highly crystalline core surrounded by less organized surface chains (Preston and Cronshaw, 1958). The proportion of surface chains whose solid state NMR signal is different from the one of the crystalline core is directly dependent on the dimensions of the microfibril (Newman, 1999). The fraction of non-crystalline cellulose chains corresponding to surface chains and amorphous regions is higher the finer the microfibril is. The amount of amorphous phase in the alga Valonia, which has large diameter microfibrils (15 to $25 \mathrm{~nm}$ ), is of the order of a few per cent, whereas it is 30 to $35 \%$ for cotton linters with a section around $7 \mathrm{~nm}$, and 65 to $70 \%$ for primary walls that have very fine microfibrils $(1.5-3 \mathrm{~nm})$. Increasing the number of molecules at the surface would result in a corresponding increase of reactivity, since the surface molecules are accessible for chemical or physical modification, while the cellulose molecules hidden inside the microfibril structure are not. The accessibility of amorphous cellulose surface chains to chemical modification may also be useful for determining the size of crystallites.

Therefore, in nature, cellulose occurs as a slender rod-like or threadlike entity, which arises from the linear association of crystallites. This entity is called the microfibril (collection of cellulose chains) and it forms the basic structural unit of the plant cell wall. Each microfibril can be considered as a string of cellulose crystallites, linked along the chain axis by amorphous domains. They are biosynthesized by enzymes and deposited in a continuous fashion. Their structure consists of a predominantly crystalline cellulose core. This is covered with a sheath of paracrystalline polyglucosan material surrounded by hemicelluloses.

Different models have been proposed in the literature for the fibrillar structure of cellulose. The generally most accepted is the one suggested by Fengel (1971) for the ultrastructure organization of the cell wall components in wood which had several layers of hemicellulose molecules between the fibrils (dimensions $12.0 \mathrm{~nm}$ ) and a monomolecular layer of hemicellulose between the elementary fibrils. Lignin was envisaged as surrounding the total microfibrillar system as shown in Figure 1.9 (Fengel, 1971). Fengel and Wegener (1984) present an accurate model that considers the intimate links between hemicellulose and cellulose on the one hand, and hemicellulose and lignin on the other. In this model, the microfibrils of cellulose, the less ordered cellulose chains and hemicelluloses associate together through many hydrogen bonds. On the other hand, hemicellulose is more strongly linked to lignin by covalent bonds. The Fengel model is relatively comprehensive, but does not fully take into 


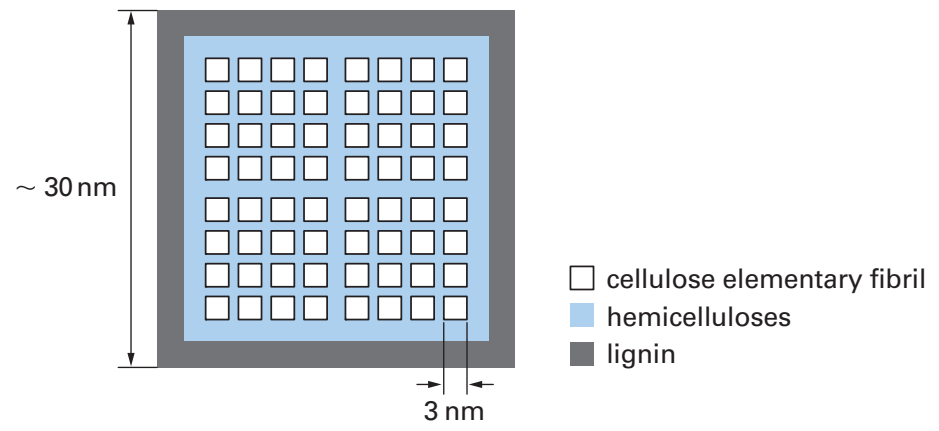

Fig. 1.9: Model of the wood cellulose microfibril structure, consisting of elementary nanofibrils. Adapted from Fengel and Wegener (1984).

account the composite nature of the cellulose microfibrils (crystalline and amorphous parts). Indeed, if one considers a single macromolecule of cellulose, some parts of it are found in the crystalline parts, while others integrate less ordered areas.

Taylor and Wallace (1989) discussed the effect of the hemicellulose xyloglucan binding to the fibrils. The extent of the association between cellulose and xyloglucan is dependent on the source of cellulose (Hayashi and Maclachlan, 1984). Binding of xyloglucan has been suggested as a regulator of cellulose fibrillar size (Sasaki and Taylor, 1984).

\subsection{Hierarchical structure of plants and natural fibers}

The term "natural fibers" covers a broad range of vegetable, animal, and mineral fibers. However, in the composites industry, it usually refers to wood fibers and agrobased bast, leaf, seed, and stem fibers. Natural fibers are not limited to a macroscopic view of cellulose. A more intimate insight accounts for hierarchical assemblies of microfibers called microfibrils, which are themselves the product of the supramolecular architecture of the basic polymer, namely cellulose as shown in Section 1.5.

Wood and plants are cellular hierarchical biocomposites designed by nature and they are basically semicrystalline cellulose microfibril-reinforced amorphous matrices made of hemicellulose, lignin, waxes, extractives and trace elements. Lignocellulosic fibers consist therefore of microfibrils aggregate. The primary cell wall is then essentially a composite material consisting of a framework of cellulose microfibrils embedded in a cementing matrix of other, mostly hemicelluloses and lignin, polymers. Hemicellulose is not a form of cellulose but falls into a group of polysaccharides (with the exception of pectin) attached to the cellulose after the lignin has been removed. However, their structure contains many different sugar units, apposed to the D-anhydroglucose units in cellulose, and is a highly branched polymer com- 
pared to the linearity of cellulose. Lignin is generally considered as a little understood hydrocarbon polymer with a highly complex structure consisting of aliphatic and aromatic constituents and forms the matrix sheath around the fibers that holds the natural structure (e.g. trees) together.

The structure of plants spans many length scales, like many other biological tissues including bones (this basic structure of all vertebrates is made of collagen fibrils embedded in an inorganic apatite matrix) and teeth, in order to provide maximum strength with a minimum of material. Wood, which is approximately 40-50 wt \% cellulose with about half in nanocrystalline form and half in amorphous form, is a well-known example (Figure 1.10). Meters describe the whole tree, centimeters describe structures within the cross-section, millimeters describe growth rings, tens of micrometers the cellular anatomy, micrometers describe the layer structure within cell walls, tens of nanometers describe the configuration of cellulose fibrils in a matrix mainly composed of hemicellulose and lignin, and nanometers describe the molecular structures of cellulose, hemicellulose, and lignin and their chemical interactions (Moon, 2008).

From a structural point of view, natural fibers are multicellular in nature and consist of bundles of elongated mostly cylindrical honeycomb cells which have differ-

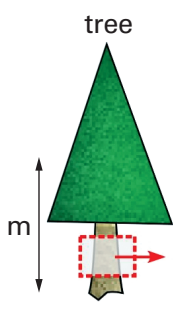

(a)

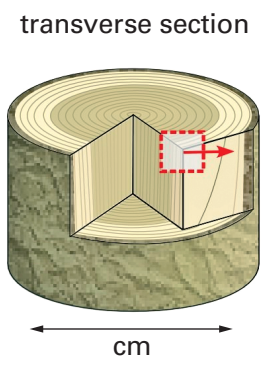

(b)

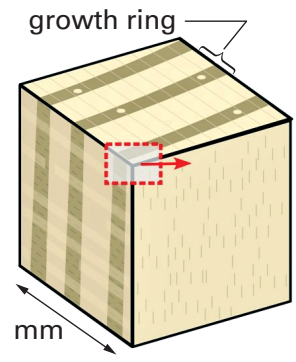

(c)

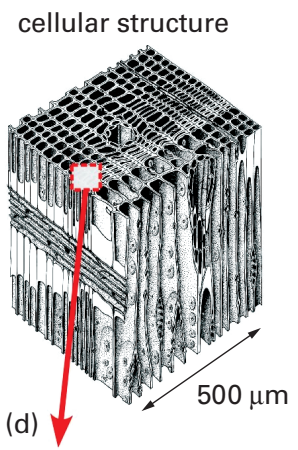

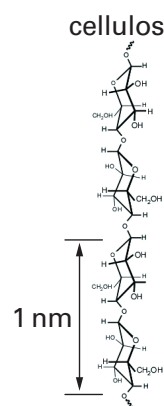

(h)

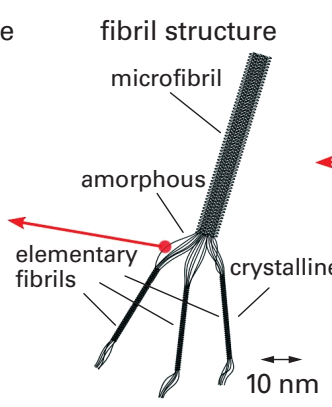

(g) fibril-matrix structure

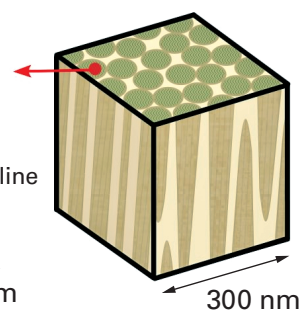

(f)

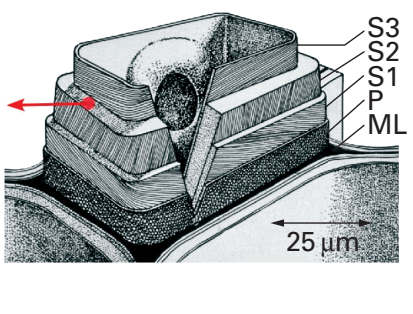

(e)

Fig. 1.10: Wood hierarchical structure: from tree to cellulose (Moon, 2008). 
ent sizes, shapes and arrangements depending on the source of plant fiber. These cells are cemented together by an intercellular substance which is isotropic, non-cellulosic and ligneous in nature. They are like microscopic tubes, i.e. cell walls surrounding the center lumen that contribute to the water uptake behavior of plant fibers (Figure 1.11). Therefore, natural fibers present a multi-level organization and consist of several cells formed out of semicrystalline oriented cellulose microfibrils connected to a complete layer by lignin, hemicelluloses and in some cases pectins. Table 1.1 reports the mean chemical composition of some natural fibers. These values are obviously only indicative since climatic conditions, age and digestion process influence not only the structure of fibers but also their chemical composition. With the exception of some species, like cotton, nettle and others, the components of natural fibers are cellulose, hemicelluloses and lignin which are the basic components with regard to the physical properties of the fibers.

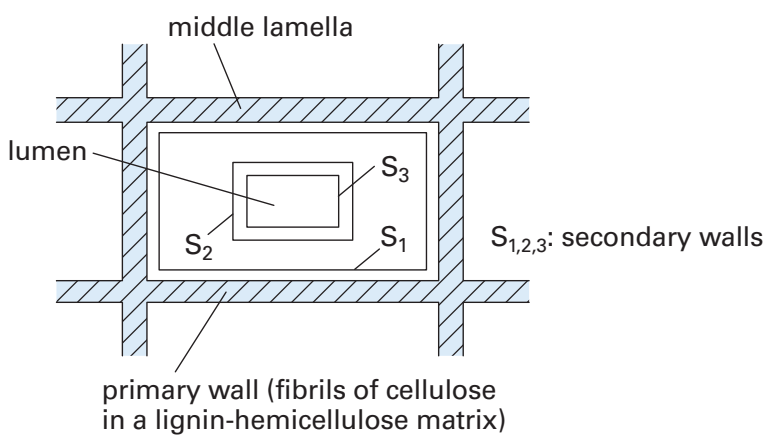

Fig. 1.11: Schematic structure of a natural fiber cell (Bismarck et al., 2002).

Cell wall architectures are the nanodimensional structures composed of multiple elementary nanofibril arrangements. Cellulose fibrils self-assemble in a manner similar to liquid crystals leading to nanodimensional structures seen in typical plant cell walls. The cell walls differ in both their composition and orientation of cellulose microfibrils. In most plant fibers, the cellulose microfibrils in the central walls, the major part of the cell wall representing up to $86 \%$ of the cell wall (Fengel and Stoll, 1973) is labeled S2, form a constant angle to the normal axis called the microfibrillar angle (Figure 1.12). The normal axis corresponds to the longitudinal direction of the tracheid (i.e. of the stem or of the branch). In the second largest layer of the cell wall, labeled S1, the fibrils run at a gentle helical slope roughly perpendicular to the ones in the S2 (Fengel and Wegener, 1984; Reiterer et al., 1998).

The characteristic value for this structural parameter varies from one plant fiber to another and the crystallites are therefore arranged in a spiral form, the pitch of which is specific of a given source. The spiral angle in the S2 (as in the other different cell wall layers) can be measured using polarized light microscopy (Preston, 1934; 


\begin{tabular}{lllll} 
Fiber & Cellulose (wt\%) & Hemicellulose (wt\%) & Lignin (wt\%) & Waxes (wt\%) \\
\hline Abaca & $56-63$ & $20-25$ & $7-9$ & 3 \\
Alfa & 45.4 & 38.5 & 14.9 & 2 \\
Bagasse & 55.2 & 16.8 & 25.3 & - \\
Bamboo & $26-43$ & 30 & $21-31$ & - \\
Banana & $63-64$ & 19 & 5 & - \\
Coir & $32-43$ & $0.15-0.25$ & $40-45$ & - \\
Cotton & $85-90$ & 5.7 & - & 0.6 \\
Curaua & 73.6 & 9.9 & 7.5 & - \\
Flax & 71 & $18.6-20.6$ & 2.2 & 1.5 \\
Hemp & 68 & 15 & 10 & 0.8 \\
Henequen & 60 & 28 & 8 & 0.5 \\
Isora & 74 & - & 23 & 1.09 \\
Jute & $61-71$ & $14-20$ & $12-13$ & 0.5 \\
Kenaf & 72 & 20.3 & 9 & \\
Kudzu & 33 & 11.6 & 14 & - \\
Nettle & 86 & 10 & - & 4 \\
Oil Palm & 65 & - & 29 & - \\
Piassava & 28.6 & 25.8 & 45 & - \\
Pineapple & 81 & - & 12.7 & - \\
Ramie & $68.6-76.2$ & $13-16$ & $0.6-0.7$ & 0.3 \\
Sisal & 65 & 12 & 9.9 & 2 \\
Sponge Gourd & 63 & 19.4 & 11.2 & 3 \\
Sun Hemp & $41-48$ & $8.3-13$ & 22.7 & - \\
Wheat Straw & $38-45$ & $15-31$ & $12-20$ & - \\
\hline & & & &
\end{tabular}

Table 1.1: Chemical composition of various natural fibers (Valadez-Gonzalez et al., 1999; Hattallia et al., 2002; Hoareau et al., 2004).

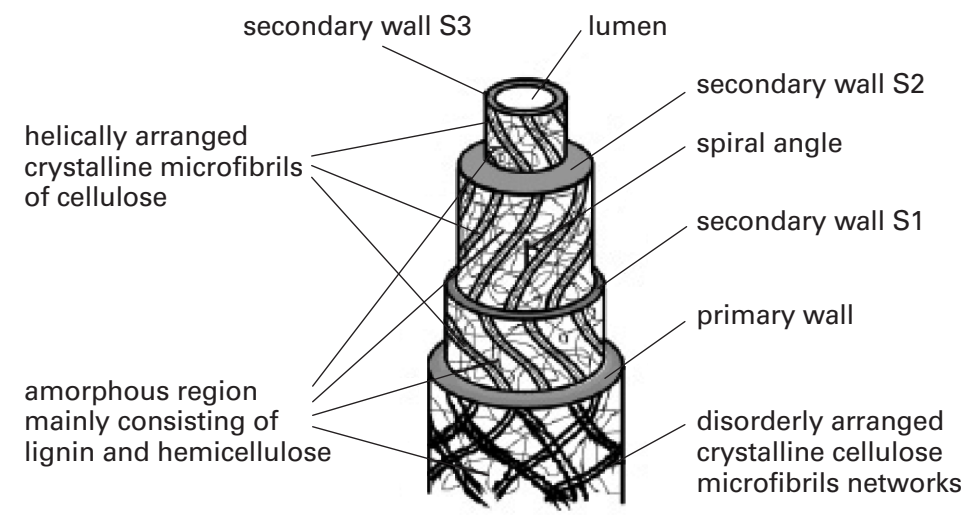

Fig. 1.12: Schematic structure of an elementary plant fiber (cell). The secondary cell wall, S2, makes up about 80 per cent of the total thickness (Rong et al., 2001). 
Boyd and Foster, 1974), staining methods for microscopic investigations (Hiller, 1964; El-Osta et al., 1972), X-ray diffraction methods (Kantola and Seitsonen, 1961; Kantola and Seitsonen, 1969; El-Osta et al., 1972; El-Osta, 1973; Paakkari and Serimaa, 1984) and small-angle X-ray scattering (Jakob et al., 1994; Reiterer et al., 1998). Hence the properties of the single fibers depend on the crystallite content, their sizes, shape, orientation, length/diameter (L/D) or aspect ratio of cells, thickness of cell walls, and finally, lumen. In general, the fiber strength increases with increasing cellulose content and decreasing spiral angle with respect to fiber axis. The most important factor controlling the different types of natural fibers is their species because the properties of fibers are different between different species. In addition, the properties of fibers within a species vary depending on area of growth, climate and age of the plant. Lastly, the properties of natural fibers vary greatly depending on the processing method used to break down the lignocellulosic substrate to the fiber level.

The outer cell wall is porous and contains almost all of the non-cellulose compounds, except proteins, inorganic salts and coloring matter and it is this outer cell wall that creates poor absorbency, poor wettability and other undesirable textile properties. In most applications, fiber bundles or strands are used rather than individual fibers. Within each bundle the fiber cells overlap and are bonded together by pectins that give strength to the bundle as a whole. However, the strength of the bundle structure is significantly lower than that of the individual fiber cell. Then the potential of individual fibers is not fully exploited.

Multiple such cellulose-lignin/hemicellulose layers in one primary and three secondary cell walls stick together to a multiple-layer-composite. Such microfibrils have typically a diameter of about 2-20 nm, are made up of 30 to 100 cellulose molecules in extended chain conformation and provide the mechanical strength to the fiber. The degree of crystallinity and typical dimensions of cellulose microfibrils depend on their origin, although the biosynthetic mechanism is the same in all organisms (Sarko and Muggli, 1974; Woodcock and Sarko, 1980).

\subsection{Potential reinforcement of cellulose}

To be potentially mechanically effective, reinforcement must have a modulus and strength that greatly exceed those of the continuous medium in which it is dispersed. This stiffening is generally obtained at the expense of the ductility or plasticity of the material that becomes more brittle. The modulus of glassy and rigid crystalline polymers is of the order of a few $10^{9} \mathrm{~Pa}$, i.e. a few GPa. Therefore, the modulus of cellulosic particles must be significantly higher than this value to be exploitable and potentially usable as a load-bearing element for glassy polymers. In addition, it must be homogeneously dispersed and distributed, and the level of adhesion between both phases should be sufficient to allow proper stress transfer from the matrix to the reinforcing phase across the interface upon loading. 
In nature, cellulose is a ubiquitous structural polymer that confers its mechanical properties to higher plant cells. The hierarchical structure of natural fibers, based on their elementary nanofibrillar components, leads to the unique strength and high performance properties of different species of plants. Indeed, the most important attribute of wood and other lignocellulosic materials is their mechanical properties, in particular their unusual ability to provide high mechanical strength and high strength-to-weight ratio while allowing for flexibility to counter large dimensional changes due to swelling and shrinking. In all terrestrial and aquatic plant species, the primary cell wall is a dynamic structure and its constituting material must be synthesized in a form that is competent to undergo extension.

The mechanical properties of cellulose can be characterized by its properties in both the ordered (so-called crystalline) and disordered (so-called amorphous) regions of the molecule. The chain molecules in the disordered regions contribute to the flexibility and the plasticity of the bulk material, while those in the ordered regions contribute to the stiffness and elasticity of the material. As they are almost defect-free, the modulus of cellulosic nanocrytals is close to the theoretical limit for cellulose. The promise behind cellulose-derived composites lies in the fact that the axial specific Young's modulus (modulus-to-density ratio) of the basic cellulose crystal derived from theoretical chemistry is potentially stronger than steel and similar to Kevlar.

\subsubsection{Mechanical properties of natural fibers}

The properties of natural fibers are strongly influenced by many factors, particularly chemical composition and location in plants. In most natural fibers the microfibrils orient themselves at an angle to the fiber axis called the microfibril angle. A weak correlation between strength and cellulose content and microfibril or spiral angle is found for different plant fibers (Lee and Rowell, 1991). In general, fiber strength increases with increasing cellulose content and decreasing spiral angle with respect to fiber axis. This means that the most efficient cellulose fibers are those with high cellulose content and low microfibril angle. Other factors that may affect the fiber properties are maturity, separating process, microscopic and molecular defects such as pits and nodes, type of soil and weather conditions under which they were grown.

The mechanical properties reported in the literature for some plant fibers are collected in Table 1.2. They are generally determined from tensile tests performed on more or less individual fibers (bundles of fiber) despite a great variability of results. The experimental conditions (temperature and relative humidity) should be strictly controlled because of the great variability of the properties of natural fibers with respect to these parameters. A circular cross section is generally assumed to calculate the cross-sectional area of the sample and thus convert the applied load into stress. For statistical significance a large number of tests are required (Eichhorn et al., 2000). These mechanical properties are much lower when compared to those of the 
most widely-used competing reinforcing glass fibers. However, because of their lower density, the specific properties (property-to-density ratio), strength, and stiffness of plant fibers are comparable to the values of glass fibers (Bismarck et al., 2005).

\begin{tabular}{|c|c|c|c|c|c|}
\hline Fiber & $\begin{array}{l}\text { Density } \\
\left(\mathrm{g} \cdot \mathrm{cm}^{-3}\right)\end{array}$ & $\begin{array}{l}\text { Diameter } \\
(\mu \mathrm{m})\end{array}$ & $\begin{array}{l}\text { Tensile Strength } \\
\text { (MPa) }\end{array}$ & $\begin{array}{l}\text { Young's Modulus } \\
\text { (GPa) }\end{array}$ & $\begin{array}{l}\text { Elongation at } \\
\text { break (\%) }\end{array}$ \\
\hline Flax & 1.5 & $40-600$ & $345-1,500$ & 27.6 & $2.7-3.2$ \\
\hline Hemp & 1.47 & $25-500$ & 690 & 70 & 1.6 \\
\hline Jute & $1.3-1.49$ & $25-200$ & $393-800$ & $13-26.5$ & $1.16-1.5$ \\
\hline Kenaf & & & 930 & 53 & 1.6 \\
\hline Ramie & 1.55 & & $400-938$ & $61.4-128$ & $1.2-3.8$ \\
\hline Nettle & & & 650 & 38 & 1.7 \\
\hline $\begin{array}{l}\text { Sisal } \\
\text { Henequen }\end{array}$ & 1.45 & $50-200$ & $468-700$ & $9.4-22$ & $3-7$ \\
\hline PALF & & $20-80$ & $413-1,627$ & $34.5-82.5$ & 1.6 \\
\hline Abaca & & & $430-760$ & & \\
\hline $\begin{array}{l}\text { Oil Palm EFB } \\
\text { (empty fruit } \\
\text { bunch) }\end{array}$ & $0.7-1.55$ & $150-500$ & 248 & 3.2 & 25 \\
\hline $\begin{array}{l}\text { Oil Palm } \\
\text { Mesocarp }\end{array}$ & & & 80 & 0.5 & 17 \\
\hline Cotton & $1.5-1.6$ & $12-38$ & $287-800$ & $5.5-12.8$ & $7-8$ \\
\hline Coir & $1.15-1.46$ & $100-460$ & $131-220$ & $4-6$ & $15-40$ \\
\hline E-glass & 2.55 & $<17$ & 3,400 & 73 & 2.5 \\
\hline Kevlar & 1.44 & & 3,000 & 60 & $2.5-3.7$ \\
\hline Carbon & 1.78 & $5-7$ & $3,400-4,800$ & $240-425$ & $1.4-1.8$ \\
\hline
\end{tabular}

Table 1.2: Characteristic values for the density, diameter and mechanical properties of vegetable and synthetic fibers (Bismarck et al., 2005).

Raman spectroscopy is an invaluable method for evaluating changes that occur in a fiber structure subjected to a mechanical solicitation, i.e. stress and strain (Eichhorn et al., 2001a). With this method, the molecular deformation mechanisms of the polymeric chains can be examined through the large stress-induced Raman band shifts that can occur during deformation. Therefore, the technique relies on the accurate measurement of the position of a structurally characteristic Raman band as a function of external deformation of the fiber, whether in air or when incorporated into a composite material. It has been successfully applied to study deformation processes for a wide variety of aromatic high-modulus polymeric fibers (Yeh and Young, 1999). The Raman peak shifts towards lower wavenumbers are thought to correspond to the direct deformation of bonds within the cellulose chain structure as first demonstrated and predicted theoretically for polydiacetylene single crystals (Batchelder and Bloor, 1979). 
For cellulose, the positions of characteristic bands located at 1414, 1095 and $895 \mathrm{~cm}^{-1}$ have been reported to shift (Hamad and Eichhorn, 1997; Eichhorn et al., 2000; Eichhorn and Young, 2003; Eichhorn and Young, 2004; Gierlinger et al., 2006; Peetla et al., 2006; Tze et al., 2006; Tze et al., 2007). For a number of cellulosic materials (regenerated and natural fibers, wood, and paper), it was reported that during tensile deformation the highest intensity Raman band located at $1095 \mathrm{~cm}^{-1}$, corresponding to the stretching mode of $\mathrm{C}-\mathrm{O}$ within the ring structure of cellulose (Blackwell et al., 1970; Attala, 1976), shifted towards lower wavenumbers and was most indicative of the molecular deformation (Hamad and Eichhorn, 1997; Eichhorn et al., 2001a). An example of the effect of deformation on the position of the Raman band initially located at $1095 \mathrm{~cm}^{-1}$ for coir fibers is shown in Figure 1.13(a). This effect is indicative of the stress level in the fibers. An example of a typical shift Raman peak in the $1095 \mathrm{~cm}^{-1}$ peak position with strain for a fibrous fragment of microcrystalline cellulose in an epoxy resin is shown in Figure 1.13(b). Moreover, the rate of Raman band shift was shown to be invariant with stress, which is consistent with a fiber structure based on a modified series aggregate model. Since the Raman band located at $1095 \mathrm{~cm}^{-1}$ is associated with the backbone of cellulose, its intensity is sensitive to the orientation of these chains with respect to the polarization direction of the laser (Bakri and Eichhorn, 2010). After the fiber failed, the band was found on its original position again, proving the elastic nature of the deformation (Gierlinger et al., 2006).

Fourier transform near-infrared (FT-NIR) Raman microspectroscopy was used to investigate the micromechanical tensile deformation behavior of hemp fibers (Peetla et al., 2006). Mechanical properties were accessed for different dew-retting durations and alkali chemical treatments with aqueous sodium hydroxide solutions (mercerization treatment) of different concentrations. The macroscopic results (tensile tests) were found to be in accordance with the microscopic results. The tensile modulus and

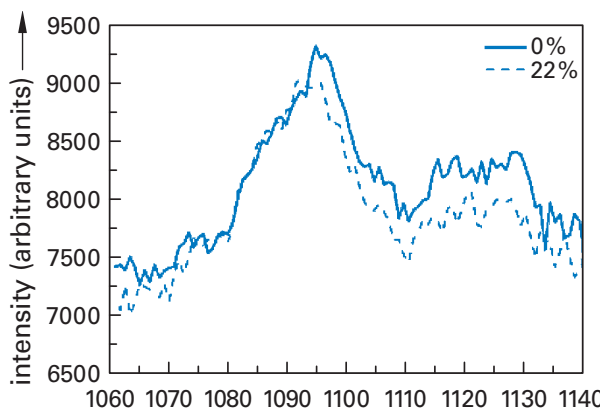

(a)

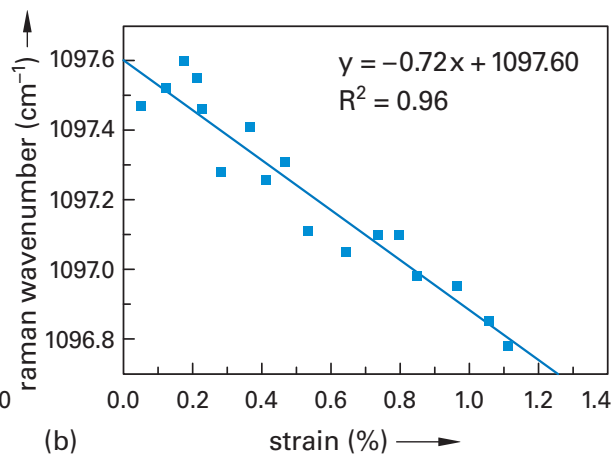

(b)

Fig. 1.13: (a) Example of a typical shift in the position of the Raman band initially located at $1095 \mathrm{~cm}^{-1}$ for a coir fiber deformed in tension (Bakri and Eichhorn, 2010). The strain rate is indicated in the Figure. (b) Typical shift of the $1095 \mathrm{~cm}^{-1}$ Raman peak for a fibrous fragment of microcrystalline cellulose (Eichhorn and Young, 2001). 
tensile strength ranged between 7.8 and $12.8 \mathrm{GPa}$, and 93 and $250 \mathrm{MPa}$, respectively, depending on the retting level, and decreased down to $4.7 \mathrm{GPa}$ and $74 \mathrm{MPa}$, respectively, for hemp fibers treated under strong mercerization conditions. The Young's modulus of a particulate form of cellulose, namely microcrystalline cellulose, was estimated from the values of the shift rate of the $1095 \mathrm{~cm}^{-1}$ Raman band with strain (Eichhorn and Young, 2001). This shift was monitored and compared to the deformation of natural fibers (flax and hemp). A value of $25 \pm 4 \mathrm{GPa}$ was reported. It has been shown that this value is consistent with the degree of crystallinity of microcrystalline cellulose measured from X-ray diffraction experiments.

Another important Raman band at $1414 \mathrm{~cm}^{-1}$ is associated with 3-atom band vibrations (HCC, HCO and HOC bending) that ought to be influenced by transverse forces through side-chain hydrogen bonding. The significant shift of this peak upon deformation shows the important role of hydrogen bonding within the structure in stress-transfer between adjacent cellulose chains (Eichhorn et al., 2003). Raman spectroscopy has been shown to be also a useful tool for characterizing the orientation of the fibrillar structure in cellulosic fibers and for following their micromechanical deformation (Bakri and Eichhorn, 2010).

\subsubsection{Mechanical properties of cellulose microfibrils}

The mechanical properties of constitutive microfibrils released from lignocellulosic fibers should be less dispersed because of a more homogeneous nature. Moreover, the modulus of individual microfibrils must be higher than that of lignocellulosic fibers. However, the analysis of plant primary cell walls tissues is difficult using standard techniques. The properties of the nanoscopic fibrous components cannot be physically measured without extracting them from the tissue, which may result in significant chemical alteration and mechanical damage.

A structural approach has been used to develop a hierarchical description of plant tissue mechanical properties down to the level of cell wall components (Hepworth and Bruce, 2000). This model was used to back calculate cell wall microfibril properties. Force deflection data from the compression of cubes of potato tissues (loading rate $10 \mathrm{~mm} \cdot \mathrm{min}^{-1}$ ) were fed in a model containing two structural levels, the cell structure and the cell wall structure. Materials properties were assigned at the level of cell wall microfibrils. The modulus was found to vary with the strain and displayed a maximum value of $130 \mathrm{GPa}$. The maximum microfibril strain was chosen as the value after a tissue deformation of $22 \%$ that corresponds to the maximum tissue deformation at which the constant volume assumption was applicable at this particular rate of tissue deformation. At $8 \%$ wall strain, i.e. the value at which failures were suspected to begin, the stress was predicted to be $7.5 \mathrm{GPa}$. This value is also close to theoretical chemistry predictions of $7-8 \mathrm{GPa}$ for the strength of cellulose microfibrils and failure 
by chain scission. At larger strains the modulus decreased significantly, showing the influence of non-cellulosic polysaccharides on the microfibril properties.

Atomic force microscopy (AFM) allows the direct and accurate mechanical characterization of nanomaterials. The AFM tip can be used to measure the elastic modulus of suspended single filaments such as cellulose microfibrils by performing a nanoscale three-point bending test, in which the center of the filament is deflected by a known force (Figure 1.14). In this experiment, the AFM cantilever applies the known force on a filament bridging a gap. The stiffness of bacterial cellulose consisting of filaments with diameters ranging from 35 to $90 \mathrm{~nm}$ has been determined by this technique (Guhados et al., 2005). The sample was imaged in contact mode to locate isolated bacterial cellulose filaments that spanned the gap of a silicon-nitridecoated silicon grating with a pitch of $3.0 \mu \mathrm{m}$ and nominal step height of $1000 \mathrm{~nm}$. Once identified, the filaments were imaged at higher resolution to determine their dimensions. The cantilever deflection was recorded as a function of vertical sample displacement. In principle, the deflection of the filament is due to tensile/compressive and shear deformations. However, when the ratio of the length of filament that bridges the gap to the diameter is higher than 16, which was the case in this study, shear can be neglected. No dependence on diameter was observed, indicating that shear forces can be effectively neglected and that the filaments behave mechanically like a homogeneous material. A Young's modulus value of $78 \pm 17 \mathrm{GPa}$ was reported. This value is lower than the one reported for single filaments of bacterial cellulose (114 GPa) and obtained by following the shift of the $1095 \mathrm{~cm}^{-1}$ Raman band towards lower wavenumbers upon the application of tensile deformation (Hsieh et al., 2008). The authors explained the discrepancy with the value obtained by AFM tip bending of cellulosic filaments (Guhados et al., 2005) by the different solicitation applied to the sample, modulus values obtained in bending being expected to be different to those obtained in tension.

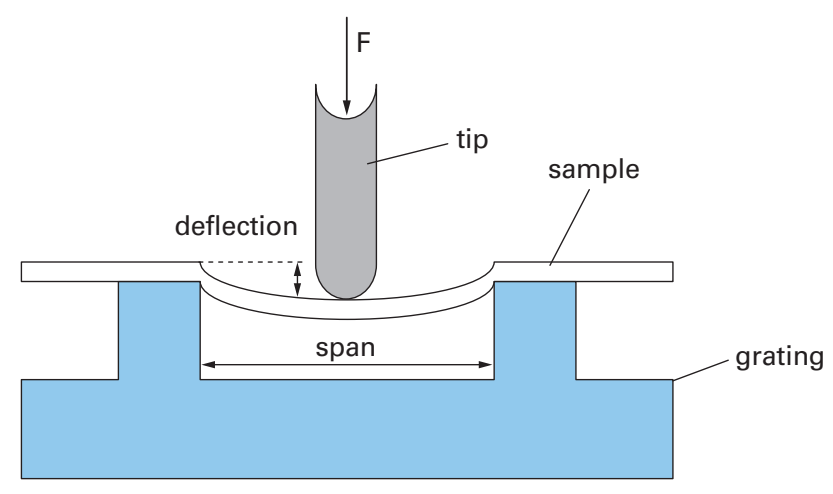

Fig. 1.14: Schematic of the measurement of the elastic modulus of single filaments using AFM by performing a nanoscale three-point bending test. 
Similar AFM tip bending experiments were performed on bundles of cellulose microfibrils and the effects of both the isolation process and the cellulose source on the elastic modulus were investigated (Cheng et al., 2009). Regenerated cellulose fibers (Lyocell), pure cellulose flours and pulp fibers were used. Defibrillation was performed by mechanical methods with high shear force, viz. ultrasonic treatment and high-pressure homogenization. Commercial microfibrillated cellulose (MFC) (Daicel Chemical Industries Ltd., Japan) was also used as reference. A broad range of diameters was obtained for cellulose microfibril bundles and only filaments with diameters in the range 150-300 nm were investigated. The cellulosic filaments were suspended over the edged groove in a silicon wafer. The wafer had grooves with $5 \mu \mathrm{m}$ in width and $1360 \mathrm{~nm}$ in depth. The elastic modulus of lyocell microfibril bundles with diameters ranging between 150 and $180 \mathrm{~nm}$ was evaluated to be $98 \pm 6 \mathrm{GPa}$. Values of $81 \pm 12$ GPa and $84 \pm 23$ were reported for pulp and MFC, respectively. These values decreased sharply for diameters above $180 \mathrm{~nm}$. The different values reported for the stiffness of cellulose microfibrils (or bundles) are collected in Table 1.3.

\begin{tabular}{llll} 
Material & Method & $\mathbf{E}_{\mathrm{L}}(\mathrm{GPa})$ & Reference \\
\hline Potato Tuber Tissue & Calculation & 130 & (Hepworth and Bruce, 2000) \\
\hline Bacterial Cellulose & AFM & $78 \pm 17$ & (Guhados et al., 2005) \\
\hline Bacterial Cellulose & Raman & 114 & (Hsieh et al., 2008) \\
\hline Lyocel Microfibrils & AFM & $98 \pm 6$ & (Cheng et al., 2009) \\
Pulp Microfibrils & & $81 \pm 12$ & \\
Commercial MFC & & $84 \pm 23$ & \\
\hline
\end{tabular}

Table 1.3: Longitudinal $\left(E_{L}\right)$ modulus of cellulose microfibrils.

\subsubsection{Mechanical properties of cellulose crystal}

The modulus of cellulose microfibrils is expected to result from a mixing rule of the modulus of the crystals, the amorphous fraction and defects/air in the sample. As for any semicrystalline polymer, the crystalline regions of cellulose act as physical crosslinks for the material. In this physically cross-linked system, the crystalline regions would also act as filler particles due to their finite size, which would increase the modulus substantially.

The elastic modulus of the crystalline region of cellulose is an important property of this material, especially with respect to the ultimate aim of exploiting its full potential in composite materials. The elastic properties of cellulose crystalline regions have been investigated since the mid-1930s either by theoretical evaluations or by experimental measurements (wave propagation, X-ray diffraction, Raman spectroscopy, 
and AFM). It was shown in 1936 (Meyer and Lotmar, 1936) that the modulus of elasticity corresponding to the principal chain direction of a polymer crystal of specified nature may be calculated from the force constants of the chemical bonds of the chain derived from vibration frequencies of molecules. Appling the method to the cellulose crystal, the authors obtained for two different estimates of force constants longitudinal modulus values of $7.7 \cdot 10^{11}$ and $12.1 \cdot 10^{11} \mathrm{dyn} \cdot \mathrm{cm}^{-2}$, i.e. 77 and $121 \mathrm{GPa}$. Another calculation of the elastic modulus of polymer crystal has been made following a method applied to other polymers by treating an isolated molecule and considering the changes in bond lengths and bond angles caused by the application of a stress (Treloar, 1960). The changes in these quantities were calculated from the appropriate force constants derived from spectroscopic data. A value of $5.65 \cdot 10^{11} \mathrm{dyn} \cdot \mathrm{cm}^{-2}$, i.e. $56 \mathrm{GPa}$ was derived for cellulose. This quite low value was assigned to the neglect of secondary forces derived from spectroscopic data.

The cellulose crystal modulus was first studied experimentally in 1962 for cellulose I (Sakurada et al., 1962) and cellulose II (Mann and Roldan-Gonzales, 1962). For cellulose I, the modulus value was determined from the crystal deformation of highly oriented fibers of bleached ramie. In this study, the experimental determination of the elastic moduli of crystalline regions of other polymers, such as polyethylene, polyvinyl alcohol, polyvinylidene chloride, polypropylene, and polyoxymethylene, was also investigated using highly oriented filaments or fibers. The lattice extension was measured by X-ray diffraction under a constant stress, so that the relaxation had no influence on the result. The fiber specimen around $35 \mathrm{~mm}$ long was mounted horizontally in stretching clamps and a constant weight was applied to the fiber by use of a pulley in order to induce a given extension. The stress in the crystalline regions was assumed to be equal to the stress applied to the sample, and this assumption of a homogeneous stress distribution was proven experimentally. At the zero position of the mount, the angle between the X-ray beam and fiber axis was $90^{\circ}$. The fiber axis was tilted by an angle $\theta$ to meet the Bragg conditions and obtain the most intense diffraction rays. The lattice extension was measured under this constant stress and similar experiments were carried out by varying the thickness of the fiber and the applied weight. Then, the stress-strain curves were plotted. The calculation of the elastic modulus was based on the assumption of the series model in which crystalline and amorphous regions alternate along the length of the fiber. A value of $134 \cdot 10^{4} \mathrm{~kg} \cdot \mathrm{cm}^{-2}$, i.e. $134 \mathrm{GPa}$, was reported for cellulose $\mathrm{I}$. The dimensions of the unit cell were $\mathrm{a}=8.35 \AA, \mathrm{b}=10.3 \AA, \mathrm{c}=$ $7.9 \AA$ (corresponding to the FIP - fiber identity period - or length of 2 glucose units), and $\beta=84^{\circ}$. Measurements were also performed under various relative humidities (Sakurada et al., 1964), for which the modulus of the macroscopic specimen changed from 12 to $27 \mathrm{GPa}$. This change was assumed to be due to the strong variability of the properties of amorphous regions upon water vapor adsorption since the modulus of crystalline domains remains unchanged when varying the atmosphere.

X-ray measurements of the elastic modulus of cellulose II crystals were performed using Fortisan H fibers (Mann and Roldan-Gonzales, 1962). The position of the 040 
reflection was measured with and without load on the fibers. The crystallographic 040 planes are perpendicular to the chain axes of the cellulosic molecules and the 040 spacing gave a measure of the length of the repeating unit of the chain. An apparent modulus value ranging between 7 and $9 \cdot 10^{11} \mathrm{dyn} \cdot \mathrm{cm}^{-2}$, i.e. 70 and $90 \mathrm{GPa}$, was calculated for crystalline regions on the basis of a series model.

The crystallite modulus of native cellulose along the chain has been calculated based on the X-ray analyzed molecular conformation and the force constants used in the vibrational analysis, i.e. which can well reproduce the actual infrared and Raman spectral data (Tashiro and Kobayashi, 1985). The molecular model was based on the result of the X-ray analysis reported by Gardner and Blackwell (1974). The dimensions of the unit cell were $\mathrm{a}=16.34 \AA \mathrm{n}, \mathrm{b}=15.72 \AA$, $\mathrm{c}=10.38 \AA$, and $\beta=97^{\circ}$. The intramolecular force constants of the valence-force-field type were adapted from Cael et al. (1975) with some modification. The calculated values were 172.9 and $70.8 \mathrm{GPa}$ when intramolecular hydrogen bonding was taken or was not taken into account, respectively. It evidenced the important role of intramolecular bonding on the determination of the crystallite modulus and chain deformation mechanism.

Molecular mechanics calculations have been performed on cellobiose to predict the modulus of elasticity of the cellulose chain (Kroon-batenburg et al., 1986). Either one or two intramolecular hydrogen bonds in cellobiose, parallel to the glycosidic linkage, were considered. The values derived from the model were 136 and $89 \mathrm{GPa}$, respectively. A good agreement was observed between these predicted data and experimental values for native (cellulose I) and regenerated (cellulose II) fibers. It was therefore concluded that the essential distinction between the conformations of the cellulose chain in the native and regenerated fibers was the number of intramolecular hydrogen bonds in the monomeric unit. This difference was supposed to be responsible for the respective values of the chain modulus in cellulose I and II.

The crystalline lattice moduli of cellulose I and II were measured by X-ray diffraction using ramie and mercerized ramie fibers (Matsuo et al., 1990). Values in the range 122-135 GPa and 106-112 GPa for cellulose I and II, respectively, were reported. It was shown that the crystal lattice moduli of cellulose I and II measured by X-ray diffraction depend upon morphological properties of the bulk specimen. Effects of the orientation factors of crystal and amorphous chains and crystallinity were considered. Numerical calculation indicated that the crystal lattice modulus measured by X-ray diffraction differs from the intrinsic lattice modulus when a parallel coupling between amorphous and crystalline phases is predominant, while both moduli were almost equal when a series coupling is predominant. The morphological dependence was found less pronounced when increasing the degree of molecular orientation and crystallinity. It was concluded that specimens with a high degree of molecular orientation and crystallinity should be used for measuring crystal lattice moduli by X-ray diffraction methods.

Theoretical evaluation of the three-dimensional elastic constants for the cellulose crystal forms I and II based on lattice dynamical treatment was reported by 
Tashiro and Kobayashi (1991). The calculated Young's modulus along the chain axis was $167.5 \mathrm{GPa}$ for form I and 162.1 GPa for form II. The lower value observed for form II was ascribed to the lower force constant value of intramolecular hydrogen bonds, showing again the importance of intramolecular hydrogen bonds, whereas the intermolecular hydrogen bonds were found to play a minor role. Anisotropy of the Young's modulus and linear compressibility in the planes perpendicular to the chain axis were also calculated. The two transverse moduli were $11 \mathrm{GPa}$ and $50 \mathrm{GPa}$.

$\mathrm{X}$-ray diffraction measurements were also used to determine the elastic modulus of the crystalline regions of cellulose polymorphs in the direction parallel to the chain axis (Nishino et al., 1995). Starting materials for cellulose I and II were purified ramie and polynosic fibers. Values of 138, 88, 87, 58 and 75 GPa were reported for cellulose I, II, III $\mathrm{I}_{\mathrm{I}} \mathrm{III}_{\mathrm{II}}$ and $\mathrm{IV}_{\mathrm{I}}$, respectively. This indicated that the skeleton conformation of the different polymorphs changed upon crystal transitions and that each was completely different from a mechanical point of view. The crystal transition induced a skeletal contraction accompanied by a change in intramolecular hydrogen bonds, which is considered to result in a drastic change in the modulus value of the cellulose polymorphs. Indeed, cellulose I that showed the highest modulus value displayed the longest fiber identity period (FIP). The elastic modulus of cellulose was also calculated for geometries obtained from numerical studies of the structure using a force field (Reiling and Brickmann, 1995). Values of 134 and $135 \mathrm{GPa}$ were reported for cellulose I, using the Reuss and Voigt limits, respectively, and a value of $83 \mathrm{GPa}$ was calculated for cellulose II.

Molecular dynamics modeling was used to investigate the structure and mechanical properties of regenerated cellulose fibers (Ganster and Blackwell, 1996). The longitudinal modulus at room temperature was determined to be $155 \mathrm{GPa}$, whereas the value in the perpendicular direction varied between 24 and $51 \mathrm{GPa}$.

Measurements of the elastic modulus of tunicin, the cellulose extracted from tunicate - a sea animal - using Raman spectroscopic technique has been reported (Šturcova et al., 2005). Epoxy/tunicin nanocomposites were deformed using a four-point bending test, and the shift in the characteristic Raman band located at $1095 \mathrm{~cm}^{-1}$ was used as an indication of the stress in the material. Furthermore, since no broadening of the Raman band upon deformation was observed, it was shown that this shift was related to direct chain stretching of cellulose and that relatively little amorphous/crystalline effects seen with semicrystalline cellulosic fibers occur. This analysis yielded a value of $143 \mathrm{GPa}$ for the elastic modulus of the cellulose nanocrystal.

The elastic modulus of the cellulose I $\beta$ crystal was also calculated by the molecular mechanics simulation technique (Tanaka and Iwata, 2006). The derived values varied from 124 to $155 \mathrm{GPa}$. The molecular mechanics modeling of the deformation of a number of proposed structures for the crystalline regions of cellulose I $\alpha$, I $\beta$ and II has been reported (Eichhorn and Davies, 2006). Chain stiffness values in the range 136-155 GPa and 116-149 GPa have been reported for cellulose I $\alpha$ and I $\beta$, respectively. 
For cellulose II the values were in the range 109-166 GPa. By removal of the hydrogen bonding in the structure, the stiffness of the chain decreased to $114-117 \mathrm{GPa}, 124-127$ GPa and 101-106 GPa for cellulose I $\alpha$, I $\beta$ and II, respectively, showing the effect of this important parameter.

The elastic modulus of cellulosic nanocrystals (inappropriately called single microfibrils in the study) prepared from tunicate was also measured by AFM using a three-point bending test (Iwamoto et al., 2009). The tunicin nanocrystals were prepared by two chemical methods, namely by oxidation of cellulose with 2,2,6,6-tetramethylpiperidine-1-oxyl radical (TEMPO) as a catalyst followed by a subsequent mechanical disintegration in water, and by sulfuric acid hydrolysis. The nanocellulosic materials were deposited on a specially designed silicon wafer with grooves 227 $\mathrm{nm}$ in width. The three-point bending test was applied using an AFM cantilever in which the AFM tip was used as the third loading point and measured the applied force and the displacement of nanocrystals that bridged the nanoscale grooves fabricated on the substrate. Values of 145 and $150 \mathrm{GPa}$ were reported for nanocrystals prepared by TEMPO-oxidation and acid hydrolysis, respectively.

A procedure was recently developed to calculate the transverse elastic modulus of cellulose nanocrystals by comparing the experimentally measured force-distance curves with 3D finite element calculations of tip indentation on the cellulose nanocrystals (Lahiji et al., 2010). The influence of relative humidity (RH) on the stiffness of cellulose nanocrystals was measured by comparing AFM measurements on the same nanoparticle under different humidity conditions ( 0.1 and 30\% $\mathrm{RH}$ ). The transverse modulus of an isolated cellulose nanocrystal was estimated to be between 18 and $50 \mathrm{GPa}$ at $0.1 \% \mathrm{RH}$ (flowing $\mathrm{N}_{2}$ gas). A minimal effect of $\mathrm{RH}$ was reported, confirming the resistance of the cellulose crystals to water penetration. The flexibility of the nanocrystals was also investigated by using the AFM tip as a nanomanipulator. It showed nanocrystal bending, but it was unclear if this resulted from single-crystal bending or multiple cellulose nanocrystals pivoting to their contact point.

The different values reported for the stiffness of cellulose nanocrystals are collected in Table 1.4. These values are comparable to those reported for aromatic ring polymers such as poly-p-phenylene terephtalamide (153-200 GPa) and poly-m-phenylene isophtalamide (88 GPa) (Tashiro et al., 1977). However, it is much lower than that $(235 \mathrm{GPa}$ ) of polyethylene, which possesses the maximum elastic modulus of the crystalline regions in the direction parallel to the chain axis (Nakamae et al., 1991). However, if the cross-sectional area of each individual molecule is considered, it is found that the modulus value is similar for cellulose and polyethylene. The different values reported for the crystal of cellulose are comparable to those reported for pure crystalline $\beta$-chitin produced by the marine diatom Thalassiosira fluviatilis (Xu et al., 1994). 


\begin{tabular}{|c|c|c|c|c|}
\hline Material & Method & $E_{L}(G P a)$ & $\mathrm{E}_{\mathrm{T}}(\mathrm{GPa})$ & Reference \\
\hline Cellulose I & Calculation & $\begin{array}{l}77-121 \\
56\end{array}$ & & $\begin{array}{l}\text { (Meyer and Lotmar, 1936) } \\
\text { (Treloar, 1960) }\end{array}$ \\
\hline $\begin{array}{l}\text { Bleached ramie } \\
\text { fibers (cellulose I) }\end{array}$ & X-ray diffraction & 134 & & (Sakurada et al., 1962) \\
\hline $\begin{array}{l}\text { Fortisan H fibers } \\
\text { (cellulose II) }\end{array}$ & X-ray diffraction & $70-90$ & & $\begin{array}{l}\text { (Mann and Roldan-Gonzales, } \\
\text { 1962) }\end{array}$ \\
\hline Cellulose I & Calculation & $\begin{array}{l}172.9^{\star} \\
70.8^{\star \star} \\
76\end{array}$ & $51-57$ & $\begin{array}{l}\text { (Tashiro and } \\
\text { Kobayashi, 1985) } \\
\text { (Jaswon et al., 1968 }\end{array}$ \\
\hline $\begin{array}{l}\text { Cellobiose } \\
\text { (two hydrogen } \\
\text { bonds - cellulose I) } \\
\text { Cellobiose } \\
\text { (one hydrogen } \\
\text { bond - cellulose II) }\end{array}$ & Calculation & $\begin{array}{l}136 \pm 6 \\
89 \pm 4\end{array}$ & & (Kroon-Batenburg et al., 1986) \\
\hline $\begin{array}{l}\text { Ramie fibers } \\
\text { (cellulose I) } \\
\text { Mercerized ramie } \\
\text { fibers (cellulose II) }\end{array}$ & X-ray diffraction & $\begin{array}{l}122-135 \\
106-112\end{array}$ & & (Matsuo et al., 1990) \\
\hline $\begin{array}{l}\text { Cellulose I } \\
\text { Cellulose II }\end{array}$ & Calculation & $\begin{array}{l}167.5 \\
162.1\end{array}$ & $\begin{array}{l}11 \\
50\end{array}$ & $\begin{array}{l}\text { (Tashiro and Kobayashi, } \\
\text { 1991) }\end{array}$ \\
\hline $\begin{array}{l}\text { Purified ramie } \\
\text { fibers (cellulose I) } \\
\text { Polynosics } \\
\text { (cellulose II) } \\
\text { Cellulose III } \\
\text { Cellulose IIIII } \\
\text { Cellulose IV }\end{array}$ & X-ray diffraction & $\begin{array}{l}138 \\
88 \\
87 \\
58 \\
75\end{array}$ & & (Nishino et al., 1995) \\
\hline $\begin{array}{l}\text { Cellulose I } \\
\text { Cellulose II } \\
\text { Cellulose II }\end{array}$ & Calculation & $\begin{array}{l}134-135 \\
83 \\
155\end{array}$ & $24-51$ & $\begin{array}{l}\text { (Reiling and Brickmann, 1995) } \\
\text { (Ganster and Blackwell, 1996) }\end{array}$ \\
\hline $\begin{array}{l}\text { Cellulose } I_{\alpha} \\
\text { Cellulose } I_{\beta}\end{array}$ & Calculation & $\begin{array}{l}127.8 \\
115.2\end{array}$ & & (Neyertz et al., 2000) \\
\hline $\begin{array}{l}\text { Cellulose } I_{\beta} \\
\text { Cellulose } I_{\beta}\end{array}$ & $\begin{array}{l}\text { Raman } \\
\text { Calculation }\end{array}$ & $\begin{array}{l}143 \\
124-155\end{array}$ & & $\begin{array}{l}\text { (Šturcova et al., 2005) } \\
\text { (Tanaka and Iwata, 2006) }\end{array}$ \\
\hline Cellulose $\mathrm{I}_{\alpha}$ & Calculation & $\begin{array}{l}136-155^{*} \\
114-117^{* *}\end{array}$ & & (Eichhorn and Davies, 2006) \\
\hline Cellulose $I_{\beta}$ & & $\begin{array}{l}116-149^{*} \\
124-127^{* *}\end{array}$ & & \\
\hline Cellulose II & & $\begin{array}{l}109-166^{*} \\
101-106^{* *}\end{array}$ & & \\
\hline
\end{tabular}




\begin{tabular}{|c|c|c|c|c|}
\hline Material & Method & $\mathrm{E}_{\mathrm{L}}(\mathrm{GPa})$ & $\mathrm{E}_{\mathrm{T}}(\mathrm{GPa})$ & Reference \\
\hline Cellulose $I_{\beta}$ & Calculation & $\begin{array}{l}156 \text { at } 300 \mathrm{~K} \\
117 \text { at } 500 \mathrm{~K}\end{array}$ & & (Bergenstråhle et al., 2007) \\
\hline $\begin{array}{l}\text { Cellulose I } \\
\text { Ramie fibers } \\
\text { (cellulose I) }\end{array}$ & $\begin{array}{l}\text { Raman } \\
\text { Inelastic X-ray } \\
\text { scattering }\end{array}$ & $\begin{array}{l}57-105 \\
220\end{array}$ & 15 & $\begin{array}{l}\text { (Rusli and Eichhorn, 2008) } \\
\text { (Diddens et al., 2008) }\end{array}$ \\
\hline $\begin{array}{l}\text { TEMPO-oxidized } \\
\text { Cellulose } I_{\beta} \\
\text { Acid hydrolyzed } \\
\text { Cellulose } I_{\beta}\end{array}$ & AFM & $\begin{array}{l}145 \\
150\end{array}$ & & (Iwamoto et al., 2009) \\
\hline Wood & AFM & & $18-50$ & (Lahiji et al., 2010) \\
\hline $\begin{array}{l}\text { Disaccharide } \\
\text { cellulose } I_{\beta} \\
\text { Disaccharide } \\
\text { cellulose } I_{\beta} \\
\text { Extended } \\
\text { cellulose } I_{\beta} \text { chains } \\
\text { (10-40 glucoses) }\end{array}$ & Calculation & $\begin{array}{l}85.2^{\star} / 37.6^{\star \star} \\
99.7^{\star} / 33.0^{\star \star} \\
126.0^{\star} / 63.3^{\star \star}\end{array}$ & & (Cintrón et al., 2011) \\
\hline
\end{tabular}

* with intramolecular hydrogen bondings

** without intramolecular hydrogen bondings

Table 1.4: Longitudinal $\left(E_{L}\right)$ and transverse $\left(E_{T}\right)$ moduli of crystalline cellulose.

These impressive mechanical properties make cellulose nanoparticles ideal candidates for the processing of reinforced polymer composites. Incorporating these nanoparticles in a synthetic or natural polymeric matrix consists therefore in biomimeting nature. All what scientists need to do is to try to mimic nature or to exploit natural biocomposites in order to develop novel materials that can be suitable to our needs without being harmful to the environment.

\subsection{Cellulose-based materials}

There is a growing interest in the utilization of biological materials, such as wood, not only as construction materials or as raw material for pulp and paper production, but also as a new feedstock for the development of advanced materials with tailor-made properties. Indeed, many commonly-used polymeric materials pose problems at the end of their intended life and are derived from petroleum. The fast-paced consumption of petroleum, roughly 100,000 times faster than nature can replenish it, and the general disposal possibilities, incineration and land filling, contribute to the unsustainability of the current situation (Netravali and Chabba, 2003). General solutions to this problem can focus either on the supply side, the life-end side, or on both at 
the same time. A vast amount of publications are available with work focusing on the development of polymers from renewable materials and on biodegradable polymers and composites (Mohanty et al., 2000; Rouilly and Rigal, 2002; Flieger et al., 2003; Bastioli, 2005; Wool and Sun, 2005; Yu et al., 2006).

Replacement of conventional plastics by degradable polymers, particularly for short-lived applications such as packaging, catering, surgery or hygiene, is of major interest for different actors in socio-economic life (from the plastics industry to the citizen). The potential of biodegradable polymers and more specifically of polymers derived from agro-resources, such as polysaccharides, has long been recognized. However, to date, these agro-polymers largely used in some applications (e.g. the food industry) have not found extensive applications in non-food industries, although they could be an interesting way to overcome the limitation of the petrochemical resources in the future. Material valorization implies some limitations linked to difficulties in achieving accurate and economically viable outlets.

Cellulose and more generally polysaccharides present some well-known advantages, namely low cost, lightweight, renewable character, high specific strength and modulus, availability in a variety of forms throughout the world, reactive surface and the possibility to generate energy, without residue, after burning at the end of their life cycle.

Two main groups of cellulose-based materials can be basically distinguished, viz. thermoplastically processable cellulose derivatives, such as esters, which can be used for extrusion and molding, and cellulose composites suitable only for treatment in conventional processes. Cellulose as a material is used by the natural world in the construction of plants and trees, and by man to make sails, ropes and clothes to name but a few examples. It is also the major constituent of paper and further processing can be performed to make cellophane and rayon.

\subsubsection{Thermoplastically processable cellulose derivatives}

Cellulose was used to produce the first successful thermoplastic polymer, celluloid, by the Hyatt Manufacturing Company in 1870. The compound was first chemically synthesized (without the use of any biologically derived enzymes) in 1992, by Kobayashi and Shoda (Klemm et al., 2005). As a carbohydrate, the chemistry of cellulose is primarily the chemistry of alcohols and it forms many of the common derivatives of alcohols, such as esters, ethers, etc. The hydroxyl groups of cellulose can be partially or fully reacted with various chemicals to provide derivatives with useful properties. These derivatives form the basis for much of the industrial technology of cellulose in use today. Because of the strong hydrogen bonds that occur between cellulose chains, cellulose does not melt or dissolve in common solvents. Thus, it is difficult to convert the short fibers from wood pulp into the continuous filaments needed for artificial silk, an early goal of cellulose chemistry. Several different cellulose derivatives were 
examined as early routes to artificial silk, but only two, the acetate and xanthate esters, are of commercial importance for fibers today.

Natural fibers can be used as raw materials for cellulose production. It can be modified into cellulose esters, such as cellulose acetate, cellulose acetate propionate, and butyrate, which are currently used as major components of thermoplastics. Among the esters, cellulose acetate is soluble in organic solvents such as acetone and can be spun into fiber or formed into other shapes. Xanthate esters are formed when cellulose is first treated with strong alkali and then exposed to carbon disulfide. Cellulose xanthate is soluble in aqueous alkali and the resulting solution can be extruded as filaments or films. This is the basis for the viscose process for rayon manufacture. More recently, technology has been developed to form textile fibers (Lyocell) directly from wood pulp without using a derivative to facilitate dissolution. This technology is based on the ability of amine oxides, particularly N-methylmorpholine $\mathrm{N}$-oxide to dissolve unsubstituted cellulose. They are called man-made cellulosic fibers. The inorganic ester nitrocellulose was initially used as an explosive and was an early film forming material.

Ether derivatives include ethylcellulose, a water-insoluble commercial thermoplastic used in coatings, inks, binders, and controlled-release drug tablets. Other ethers are hydroxypropyl cellulose, carboxymethyl cellulose, hydroxypropyl methyl cellulose, used as a viscosity modifier, gelling agent, foaming agent and binding agent, and hydroxyethyl methyl cellulose, used in the production of cellulose films.

\subsubsection{Cellulose fiber reinforced composites}

Natural fibers such as flax, hemp, straw, kenaf and jute consist mainly of cellulose, hemicellulose and lignin, but they are usually listed as a material when used as fibers in composites. Agricultural fibers include crop residual, such as straw, stems, hulls, and milling by-products (e.g. brans) from wheat, corn, soybean, sorghum, oat, barley, rice, sugarcane, pineapple, banana, coconut and other crops. Large quantities of agricultural fibers are available and these lignocellulosic agricultural byproducts are a cheap source of cellulose fibers. The major composition of these fibers is similar to wood fibers and includes cellulose, lignin and pentosan, and makes them suitable for uses such as composite, textile, pulp and paper manufacture. In addition, biofibers can also be used to produce fuel, chemicals, enzymes and food. Wheat straw is usually used for fuel, manure, cattle feed, mulch and bedding materials for animals (Sampathrajan et al., 1992). Particleboard can be prepared using wheat straw, sunflower stalks, rice straw, cotton stalks, sugarcane bagasse, flax, maize husks and maize cobs. The production processes, structure, properties and suitability of these biofibers for various industrial applications has been analyzed (Reddy and Yang, 2005). 
Natural fibers can also be used for composites as harvested. Over the last few years a number of researchers have been involved in investigating the exploitation of cellulosic fibers as load-bearing constituents in composite materials. This considerable interest in both the literature and industry for the possibility of replacing conventional fibers such as glass is due to some well-known advantages of lignocellulosics fibers. The specific properties of this natural product, namely low cost, lightweight, renewable character, high specific strength and modulus, availability in a variety of forms throughout the world, reactive surface, non-abrasive nature and the possibility to generate energy without residue after burning at the end of their life cycle, motivate their association with organic polymers to elaborate composite materials. However, it is well known that different surface properties between the fiber and the matrix, i.e. the former is highly polar and hydrophilic while the latter is, generally, non-polar and relatively hydrophobic, impose the surface modification of the fibers' surface, in order to improve the fiber/polymer compatibility and their interfacial adhesion. Without such a treatment the stress applied to the fiber/polymer composite is not efficiently transferred from the matrix to the fiber and the beneficial reinforcement effect of the fiber remains underexploited. Likewise, the poor ability of the polymer to wet the fiber hinders the homogenous dispersion of short fibers within the polymeric matrix. The potential and applications of lignocellulosic fibers reinforced polymers have been reviewed during the last decade (Eichhorn et al., 2001b; Bledzki and Gassan, 1999; Mohanty et al., 2005).

\subsection{Conclusions}

There is a considerable interest in the possibility of replacing conventional fibers, such as glass, for polymer composite applications. It is ascribed to some well-known advantages of natural fibers. The promise behind cellulose-derived composites lies in the fact that the longitudinal modulus of the basic cellulose crystal displays a high value, around $150 \mathrm{GPa}$ as determined by theoretical evaluations or experimental measurements. The axial specific Young's modulus (modulus-to-density ratio) of the basic cellulose crystal is therefore potentially stronger than steel and similar to Kevlar. However, the full exploitation of this reinforcing capability requires the release of these nanocrystals from lignocellulosic fibers. In addition, the use of constituting cellulose microfibrils or nanocrystals instead of fibers allows overcoming the big variation properties inherent to natural products. Indeed, it is well known that the fiber properties depend on factors such as maturity, separating process, microscopic and molecular defects, type of soil and weather conditions under which they were grown. 


\subsection{References}

Almond, A. (2005). Towards understanding the interaction between oligosaccharides and water molecules. Carbohydr. Res. 340, 907-920.

Attala, R.H. (1976). Raman spectral studies of polymorphy in cellulose. Part I: celluloses I and II. Appl. Polym. Symp. 28, 659-669.

Atalla, R.H. and VanderHart, D.L. (1984). Native cellulose: a composite of two distinct crystalline forms. Science 223, 283-285.

Atalla, R.H., Whitmore, R.E. and Vanderhart, D.L. (1985). A highly crystalline cellulose from Rhizoclonium hieroglyphicum. Biopolymers, 24, 421-423.

Bakri, B. and Eichhorn, S.J. (2010). Elastic coils: deformation micromechanisms of coir and celery fibres. Cellulose 17, 1-11.

Bastioli, C. (2005). Handbook of biodegradable polymers (Rapra Technology Limited, Shawbury, Shrewsbury, Shropshire, UK).

Batchelder, D.N. and Bloor, D. (1979). Strain dependence of the vibrational-modes of a diacetylene crystal. J. Polym. Sci. Part B: Polym. Phys. 17, 569-581.

Belton, P.S., Tanner, S.F., Cartier, N. and Chanzy, H. (1989). High-resolution solid-state ${ }^{13} \mathrm{C}$ nuclear magnetic resonance spectroscopy of tunicin, an animal cellulose. Macromolecules 22, $1615-1617$.

Bergenstråhle, M., Berglund, L.A. and Mazeau, K. (2007). Thermal response in crystalline I $\beta$ cellulose: A molecular dynamics study. J. Phys. Chem. B 111, 9138-9145.

Bernstein J. (2002). Polymorphism in molecular crystals (Clarendon Press, Oxford, UK).

Bismarck, A., Aranberri-Askargorta, I., Springer, J., Lampke, T., Wielage, B., Stamboulis, A., Shenderovich, I. and Limbach, H.-H. (2002). Surface characterization of flax, hemp and cellulose fibers; surface properties and the water uptake behaviour. Polym. Compos. 23, 872-894.

Bismarck, A., Mishra, S. and Lampke T. (2005). Plant fibers as reinforcement for green composites. In: Natural fibers, biopolymers and biocomposites, A.K. Mohanty, M. Misra and L.T. Drzal, eds. (CRC Press, Taylor \& Francis Group, Bota Raton, FL), pp. 37-108.

Blackwell, J., Vasko, P.D. and Koenig, J.L. (1970). Infrared and Raman spectra of the cellulose from the cell wall of Valonia ventricosa. J. Appl. Phys. 41, 4375-4379.

Bledzki, A.K. and Gassan, J. (1999). Composites reinforced with cellulose based fibres. Prog. Polym. Sci. 24, 221-274.

Bonard, R. (1966). Kolloidstrukturen in verstreckten Hochpolymeren. Kolloid-Z 211, 14-33.

Boyd, J.D. and Foster, R.C. (1974). Tracheid anatomy changes as response to changing structural requirements of the tree. Wood Sci. Technol. 8, 91-105.

Braconnot, H. (1819). Sur la conversion du corps ligneux en gomme, en sucre, et en un acide d'une nature particulière, par le moyen de l'acide sulfurique; conversion de la même substance ligneuse en ulmine par la potasse. Ann. Chim. 12, 172-195.

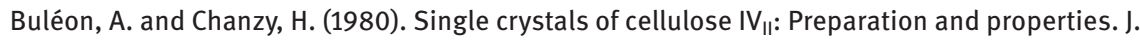
Polymer Sci, 18, 1209-1217.

Cael, J.J., Gardner, K.H., Koenig, J.L. and Blackwell, J. (1975). Infrared and Raman spectroscopy of carbohydrates. Paper. V. normal coordinate analysis of cellulose I. J. Chem. Phys. 62, 1145-1153.

Chanzy, H., Imada, K. and Vuong, R. (1978). Electron diffraction from the primary wall of cotton fibers. Protoplasma 94, 299-306.

Chanzy, H., Imada, K., Mollard, A., Vuong, R. and Barnoud, F. (1979). Crystallographic aspects of sub-elementary cellulose fibrils occurring in the wall of rose cells cultured in vitro. Protoplasma 100, 303-316. 
Chanzy, H. and Henrissat, B. (1985). Unidirectional degradation of Valonia cellulose microcrystals subjected to cellulose action. FEBS Lett. 184, 285-288.

Chanzy, H. (1990). Aspects of cellulose structure. In: Cellulose sources and exploitation, J.F. Kennedy, G.O. Phillips and P.A. Williams, eds. (Ellis Horwood Ltd, New York), pp. 3-12.

Cheng, Q., Wang, S. and Harper, D.P. (2009). Effects of process and source on elastic modulus of single cellulose fibrils evaluated by atomic force microscopy. Composites Part A 40, 583-588.

Chu, S.S.C. and Jeffrey, G.A. (1968). The refinement of the crystal structures of $\beta$-D-glucose and cellobiose. Acta Cryst. B 24, 830-838.

Cintrón, M.S., Johnson, G.P. and French, A.D. (2011). Young's modulus calculations for cellulose $I_{\beta}$ by MM3 and quantum mechanics. Cellulose 18, 505-516.

Cousins, S.K. and Brown, R.M.Jr. (1995). Cellulose I microfibril assembly: computational molecular mechanics energy analysis favours bonding by van der Waals forces as the initial step in crystallization. Polymer 36, 3885-3888.

Debzi, E.M., Chanzy, H., Sugiyama, J., Tekely, P. and Excoffier, G. (1991). The $|\alpha \rightarrow| \beta$ transformation of highly crystalline cellulose by annealing in various mediums. Macromolecules, 24, 6816-6822.

Delmer, D.P. and Amor, Y. (1995). Cellulose biosynthesis. Plant Cell 7, 987-1000.

Diddens, I., Murphy, B., Krisch, M. and Müller, M. (2008). Anisotropic elastic properties of cellulose measured using inelastic X-ray scattering. Macromolecules 41, 9755-9759.

Dolmetsch, H. and Dolmetsch, H. (1962). Evidence for the folding of the chains within the cellulose molecule. Kolloid-Z 185, 106-119.

Earl, W.L. and VanderHart, D.L. (1981). Observations by high-resolution C-13 NMR of cellulose-I related to morphology and crystal-structure. Macromolecules 14, 570-574.

Eichhorn, S.J., Hughes, M., Snell, R. and Mott, L. (2000). Strain induced shifts in the Raman spectra of natural cellulose fibers. J. Mat. Sci. Lett. 19, 721-723.

Eichhorn, S.J., Sirichaisit, J. and Young, R.J. (2001a). Deformation mechanisms in cellulose fibres, paper and wood. J. Mater. Sci. 36, 3129-3135.

Eichhorn, S.J., Baillie, C.A., Zafeiropoulos, N., Mwaikambo, L.Y., Ansell, M.P., Dufresne, A., Entwistle, K.M., Herrera-Franco, P.J., Escamilla, G.C., Groom, L., Hugues, M., Hill, C., Rials, T.G. and Wild, P.M. (2001b). Current international research into cellulosic fibres and composites. J. Mater. Sci. 36, 2107-2131.

Eichhorn, S.J. and Young, R.J. (2001). The Young's modulus of a microcrystalline cellulose. Cellulose 8, 197-207.

Eichhorn, S.J. and Young, R.J. (2003). Deformation micromechanics of natural cellulose fibre networks and composites. Compos. Sci. Technol. 63, 1225-1230.

Eichhorn, S.J., Young, R.J., Davies, R.J. and Riekel, C. (2003). Characterisation of the microstructure and deformation of high modulus cellulose fibres. Polymer 44, 5901-5908.

Eichhorn, S.J. and Young, R.J. (2004). Deformation micromechanics of hemp fibres and epoxy resin microdroplets. Compos. Sci. Technol. 64, 767-772.

Eichhorn, S.J. and Davies, G.R. (2006). Modelling the crystalline deformation of native and regenerated cellulose. Cellulose 13, 291-307.

El-Osta, M.L.M., Wellwood, R.W. and Butters, R.G. (1972). An improved X-ray technique for measuring microfibril angle of coniferous wood. Wood Sci. 5, 113-117.

El-Osta, M.L.M. (1973). A direct X-ray technique for measuring microfibril angle. Wood and Fiber 5 , 118-129.

Fengel, D. (1971). Ideas on ultrastructural organization of cell-wall components. J. Polym. Sci. Part C 36, 383-392.

Fengel, D. and Stoll, M. (1973). Über die Veränderungen des Zellquerschnittes, der Dicke der Zellwand und der Wandschichten von Fichtentracheiden innerhalb eines Jahrringes. Holzforschung 27, 1-7. 
Fengel, D. and Wegener, G. (1984). Wood: chemistry, ultrastructure, reactions. Walter de Gruyter, Berlin \& New York.

Fink, H.P., Philipp, B., Paul, D., Serimaa, R. and Paakkari, T. (1987). The structure of amorphous cellulose as revealed by wide-angle X-ray scattering. Polymer 28, 1265-1270.

Flieger, M., Kantorová, M., Prell, A., Řezanka, T. and Votruba, J. (2003). Biodegradable plastics from renewable sources. Folia Microbiol. 48, 27-44.

French, A.D., Miller, D.P. and Aabloo, A. (1993). Miniature crystal models of cellulose polymorphs and other carbohydrates. Int. J. Biol. Macromol. 15, 30-36.

Freudenberg, K. and Braun, E. (1928). Methylcellulose 5. Mitteilung über Lignin und Cellulose Ann. 460, 288-304.

Frey-Wyssling, A., Mühlethaler, K. and Wyckoff, R.W.G. (1948). Mikro-fibrillenbau der pflanzlichen Zellwande. Experientia 4, 475-476.

Frey-Wyssling, A. (1954). The fine structure of cellulose microfibrils. Science 119, 80-82

Frey-Wyssling, A. (1976). The plant cell wall (Gebruder Bornträger, Berlin).

Ganster, J. and Blackwell, J. (1996). NpH-MD-simulations of the elastic moduli of cellulose II at room temperature. J. Mol. Model. 2, 278-285.

Gardner, K.H. and Blackwell, J. (1974). The structure of native cellulose. Biopolymers 13, 1975-2001.

Gierlinger, N., Schwanninger, M., Reinecke, A. and Burgert, I. (2006). Molecular changes during tensile deformation of single wood fibres followed by Raman microscopy. Biomacromolecules 7 , 2077-2081.

Grigoriew, H. and Chmielewski, A.G. (1998). Capabilities of X-ray methods in studies of processes of permeation through dense membranes. J. Membr. Sci. 142, 87-95.

Guhados, G., Wan, W. and Hutter, J.L. (2005). Measurement of the elastic modulus of single bacterial cellulose fibers using atomic force microscopy. Langmuir 21, 6642-6646.

Hamad, W.Y. and Eichhorn, S.J. (1997). Deformation micromechanics of regenerated cellulose fibers using Raman spectroscopy. J. Eng. Mater. Technol. 119, 309-313.

Hattallia, S., Benaboura, A., Ham-Pichavant, F., Nourmamode, A. and Castellan, A. (2002). Adding value to alfa grass (Stipa tenacissima L.), soda lignin as phenolic resins. 1. Lignin characterization. Polym. Degrad. Stab. 75, 259-264.

Hayashi, J. and Maclachlan, G. (1984). Pea xyloglucan and cellulose. 2. Macromolecular organization. Cell Physiology 75, 596-604.

Hepworth, D.G. and Bruce, D.M. (2000). A method of calculating the mechanical properties of nanoscopic plant cell wall components from tissue properties. J. Mat. Sci. 35, 5861-5865.

Hess, K., Mahl, H. and Gütter, E. (1957). Electron microscopic representation of long periodic intervals in cellulose fibers and comparison with the periods of other kinds of fibers. Kolloid-Z 155, 1-19.

Hiller, C.H. (1964). Correlation of fibril angle with wall thickness of tracheids in summerwood of slash and loblolly pine. Tappi 47, 125-128.

Hoareau, W., Trindada, W.G., Siegmund, B., Castellan, A. and Frollini, E. (2004). Sugar-cane bagasse and curaua lignins oxidatized by chlorine dioxide and reacted with furfuryl alcohol: characterization and stability. Polym. Degrad. Stab. 86, 567-576.

Hon, D.N.-S. (1994). Cellulose: a random walk along its historical path. Cellulose 1, 1-25.

Hsieh, Y.-C., Yano, H., Nogi, M. and Eichhorn, S.J. (2008). An estimation of the Young's modulus of bacterial cellulose filaments. Cellulose 15, 507-513.

Irvine, J.C. and Hirst, E.L. (1923). The constitution of polysaccharides. Part VI. The molecular structure of cotton cellulose. J. Chem. Soc. 123, 518-532.

Ishikawa, A., Okano, T. and Sugiyama, J. (1997). Fine structure and tensile properties of ramie crystalline form of cellulose I, II, IIII and IV , Polymer 38, 463-468.

Iwamoto, S., Kai, W., Isogai, A. and Iwata, T. (2009). Elastic modulus of single cellulose microfibrils from tunicate measured by atomic force microscopy. Biomacromolecules 10, 2571-2576. 
Jakob, H.F., Fratzl, P. and Tschegg, S.E. (1994). Size and arrangement of elementary cellulose fibrils in wood cells: a small-angle X-ray scattering study of Picea abies. J. Struct. Biol. 113, 13-22.

Jaswon, M.A., Gillis, P.P. and Mark, R.E. (1968). The elastic constants of crystalline native cellulose. Proc. Roy. Soc. 306, 389-412.

Kantola, M. and Seitsonen, S. (1961). X-ray orientation investigations on Finnish Conifers. Ann. Acad. Sci. Fenn. A VI Phys. 80, 1-15.

Kantola, M. and Seitsonen, S. (1969). On the relation between tracheid length and microfibrillar orientation measured by X-ray diffraction in conifer wood. Ann. Acad. Sci. Fenn. A VI Phys. 300, 2-10.

Klemm, D., Heublein, B., Fink, H-P. and Bohn, A. (2005). Cellulose: fascinating biopolymer and sustainable raw material. Angew. Chem. Int. Ed., 36, 3358-3393.

Kolpak, F.J. and Blackwell, J. (1976). Determination of the structure of cellulose II. Macromolecules 9, 273-278.

Kolpak, F.J., Weih, M. and Blackwell, J. (1978). Mercerization of cellulose: Paper 1. Determination of the structure of mercerized cotton. Polymer 19, 123-131

Kovalenko, V.I. (2010). Crystalline cellulose: structure and hydrogen bonds. Russ. Chem. Rev. 79, 231-241.

Kroon-Batenburg, L.M.J., Kroon, J. and Northolt, M.G. (1986). Chain modulus and intermolecular hydrogen bonding in native and regenerated cellulose fibers. Polym. Commun. 27, 290-292.

Kuga, S., Takagi, S. and Brown, R.M.J. (1993). Native folded-chain cellulose II. Polymer 34, 3293-3297.

Lahiji, R.R., Xu, X., Reifenberger, R., Raman, A., Rudie, A. and Moon, R.J. (2010). Atomic force microscopy characterization of cellulose nanocrystals. Langmuir 26, 4480-4488.

Langan, P., Nishiyama, Y. and Chanzy, H. (1999). A revised structure and hydrogen-bonding system in cellulose II from a neutron fiber diffraction analysis. J. Am. Chem. Soc. 121, 9940-9946.

Lee, S.M. and Rowell, R.M. (1991). International encyclopedia of composites, VCH-Publishers, New York.

Lin, F.C., Brown, R.M.Jr., Cooper, J.B. and Delmer, D.P. (1985). Synthesis of fibrils in vitro by a solubilized cellulose synthase from Acetobacter xylinum. Science 230, 822-825.

Mann, J. and Roldan-Gonzales, L. (1962). X-ray measurements of the elastic modulus of cellulose crystals. Polymer 3, 549-553.

Mark, R.E., Kaloni, P.N., Tang, R.C. and Gillis, P.P. (1969). Cellulose: Refutation of a Folded Chain Structure. Science 164, 72-73.

Marszalek, P.E., Oberhauser, A.F., Pang, Y-P. and Fernandez, J.M. (1998). Polysaccharide elasticity governed by chair-boat transitions of the glucopyranose ring. Nature 396, 661-664.

Marx-Figini, M. (1964). Über die Kinetik der Biosynthese der Cellulose in der Baumwolle. Papier 18, 546-549.

Marx-Figini, M. and Schultz, G.V. (1966). Zur Biosynthese der Cellulose. Naturwissenschaften 53, 466-474.

Matsuo, M., Sawatari, C., Iwai, Y. and Ozaki, F. (1990). Effect of orientation distribution and crystallinity on the measurement by $\mathrm{X}$-ray diffraction of the crystal lattice moduli of cellulose I and II. Macromolecules 23, 3266-3275.

Meyer, K. and Lotmar, W. (1936). Sur l'élasticité de la cellulose. Helv. Chim. Acta 19, 68-86.

Mohanty, A.K., Misra, M. and Hinrichsen, G. (2000). Biofibres, biodegradable polymers and biocomposites: an overview. Macromol. Mat. Eng. 276/277, 1-24.

Mohanty, A.K., Misra, M. and Drzal, L.T. (2005). Natural fibers, biopolymers, and biocomposites (CRC Press, Taylor \& Francis Group, Boca Raton, FL).

Moon, R.J. (2008). Nanomaterials in the forest products industry (McGraw-Hill Yearbook in Science \& Technology, Chicago, IL), pp. 225-228. 
Muggli, R., Elias, H.G. and Mühlethaler, K. (1969). Zum Feinbau der Elementarfibrillen der Cellulose. Makromol. Chem. 121, 290-294.

Mühlethaler, K. (1969). Fine structure of natural polysaccharide systems. J. Polym. Sci. Part C 28, 305-316.

Nakamae, K., Nishino, T. and Okubo, M. (1991). Elastic modulus of crystalline regions of polyethylene with different microstructures: experimental proof of homogeneous stress distribution. J. Macromol. Sci. Phys. B30, 1-7.

Netravali, A.N. and Chabba, S. (2003). Composites get greener. Materials Today 6, 22-29.

Newman, R.H. (1999). Estimation of the lateral dimensions of cellulose crystallites using ${ }^{13} \mathrm{C}$ NMR signal strengths. Solid state NMR 15, 21-29.

Neyertz, S., Pizzi, A., Merlin, A., Maigret, B., Borwn, D. and Deglise, X. (2000). A new all-atom force field for crystalline cellulose. I. J. Appl. Polym. Sci. 78, 1939-1946.

Nishino, T., Takano, K. and Nakamae, K. (1995). Elastic modulus of the crystalline regions of cellulose polymorphs. J. Polym. Sci. Part B: Polym. Phys. 33, 1647-1651.

Nishiyama, Y., Langan, P., and Chanzy, H. (2002). Crystal structure and hydrogen-bonding system in cellulose $1 \beta$ from synchrotron X-ray and neutron fiber diffraction. J. Am. Chem. Soc. 124, 9074-9082.

Nishiyama, Y., Kim, U.J., Kim, D.Y., Katsumata, K.S., May, R.P. and Langan, P. (2003a). Disorder along ramie cellulose microfibrils. Biomacromolecules 4, 1013-1017.

Nishiyama, Y., Sugiyama, J., Chanzy, H. and Langan, P. (2003b). Crystal structure and hydrogen bonding system in cellulose 1 (alpha), from synchrotron X-ray and neutron fiber diffraction. J. Am. Chem. Soc. 125, 14300-14306.

Nishiyama, Y., Johnson, J.P., French, A.D., Forsyth, V.T. and Langan, P. (2008). Neutron crystallography, molecular dynamics, and quantum mechanics studies of the nature of hydrogen bonding in cellulose I- $\beta$. Biomacromolecules 9, 3133-3140.

Okamura, K. (1991). Structure of cellulose. In: Wood and Cellulosic Chemistry, D.N.-S. Hon and N. Shiraishi, ed. (Marcel Dekker, New York), pp. 89-111.

O’Sullivan, A.C. (1997). Cellulose: the structure slowly unravels. Cellulose 4, 173-207.

Paakkari, T. and Serimaa, R. (1984). A study of the structure of wood cells by X-ray diffraction. Wood Sci. Technol. 18, 79-85.

Payen, A. (1838). Mémoire sur la composition du tissu propre des plantes et du ligneux. C.R. Hebd. Seances Acad. Sci. 7, 1052-1056.

Peetla, P., Schenzel, K.C. and Diepenbrock, W. (2006). Determination of mechanical strength properties of hemp fibers using near-infrared Fourier transform Raman microspectroscopy. Appl. Spectrosc. 60, 682-691.

Preston, R.D. (1934). The organisation of the walls of conifer tracheids. Phil. Trans. B 224, 131-174.

Preston, R.D. and Cronshaw, J. (1958). Constitution of the fibrillar and non-fibrillar components of the walls of Valonia ventri- cosa. Nature 181, 248-250.

Preston, R.D. 1975. X-ray analysis and the structure of the components of plant cell walls. Physics Reports 21, 183-226.

Reddy, N. and Yang, Y. (2005). Biofibers from agricultural byproducts for industrial applications. Trends in Biotechnology 23, 22-27.

Reiling, S. and Brickmann, J. (1995). Theoretical investigations on the structure and physical properties of cellulose. Macromol. Theory Simul. 4, 725-743.

Reis, D., Vian, B., Chanzy, H. and Roland, J.-C. (1991). Liquid crystal-type assembly of native cellulose-glucuronoxylans extracted from plant cell wall. Biology of the Cell 73, 173-178.

Reiterer, A., Jakob, H.F., Stanzl-Tschegg, S.E. and Fratzl, P. (1998). Spiral angle of elementary cellulose fibrils in cell walls of Picea abies determined by small-angle X-ray scattering. Wood Sci. Technol. 32, 335-345. 
Revol, J.F., Bradford, H., Giasson, J., Marchessault, R.H. and Gray, D.G. (1992). Helicoidal self-ordering of cellulose microfibrils in aqueous suspension. Int. J. Biol. Macromol. 14, 170-172.

Roche, E. and Chanzy, H. (1981). Electron microscopy study of the transformation of cellulose I into cellulose III, in Valonia. Int. J. Biol. Macromolecules 3, 201-206.

Rong, M.Z., Zhang, M.Q., Liu, Y., Yang, G.C. and Zeng, H.M. (2001). The effect of fiber treatment on the mechanical properties of unidirectional sisal-reinforced epoxy composites. Compos. Sci. Technol. 61, 1437-1447.

Rouilly, A. and Rigal, L. (2002). Agro-materials: a bibliographic review. J. Macromol. Sci. Polym. Rev. C42, 441-479.

Rusli, R. and Eichhorn, S.J. (2008). Determination of the stiffness of cellulose nanowhiskers and the fiber-matrix interface in a nanocomposite using Raman spectroscopy. Appl. Phys. Lett. 93, 033111.

Sakurada, I., Nukushina, Y. and Ito, T. (1962). Experimental determination of the elastic modulus of crystalline regions oriented polymers. J. Polym. Sci. 57, 651-660.

Sakurada, I., Ito, T. and Nakamae, K. (1964). Elastic moduli of polymer crystals for the chain axial direction. Makromol. Chem. 75, 1-10.

Sampathrajan, A., Vijayaraghavan, N.C. and Swaminathan, K.R. (1992). Mechanical and thermal properties of particle boards made from farm residues. Bioresour. Technol. 40, 249-251.

Sandermann, W. (1973). Die “wahren” Dimensionen im Makromolekularen Bereich. Holz Roh-Werkst. $31,11$.

Sarko, A. and Muggli, R. (1974). Packing analysis of carbohydrates and polysaccharides. III. Valonia cellulose and cellulose II. Macromolecules 7, 486-494.

Sarko, A., Southwick, J. and Hayashi, J. (1976). Packing analysis of carbohydrates and polysaccharides 7. Crystal structure of cellulose $\mathrm{III}_{\mathrm{I}}$ and its relationship to other cellulose polymorphs. Macromolecules 9, 857-863.

Sarko, A. (1987). Cellulose - how much do we know about its structure? In: Wood and Cellulosics: Industrial utilization, biotechnology, structure and properties, J.F. Kennedy, ed. (Ellis Horwood, Chichester, UK), pp. 55-70.

Sasaki, K. and Taylor, I.E.P. (1984). Specific labelling of cell-wall polysaccharides with myo-[2-H-3]inositol during germination and growth of Phaseolus-vulgaris L. Cell Physiology 25, 989-997.

Sassi, J.F. and Chanzy, H. (1995). Ultrastructural aspects of the acetylation of cellulose. Cellulose 2, 111-127.

Saxena, I.M. and Brown, R.M.Jr. (2000a). Cellulose biosynthesis: a model for understanding the assembly of biopolymers. Plant Physiol. Biochem. 38, 57-67.

Saxena, I.M. and Brown, R.M.Jr. (2000b). Cellulose synthases and related enzymes. Current Opinion in Plant Biology 3, 523-531.

Saxena, I.M. and Brown, R.M.Jr. (2005). Cellulose biosynthesis: Current views and evolving concepts. Ann. Botany 96, 9-21.

Sisson, W. (1938). The existence of mercerized cellulose and its orientation in Halicystis as indicated by $x$-ray diffraction analysis. Science $87,350-351$

Sjoström, E. (1981). Wood chemistry fundamentals and applications (Academic Press Inc., New York).

St John Manley, R. (1964). Fine structure of native cellulose microfibrils. Nature 204, 1155-1157.

Stipanovic, A.J. and Sarko, A. (1976). Packing analysis of carbohydrates and polysaccharides. 6. Molecular and crystal structure of regenerated cellulose II. Macromolecules 9, 851-857.

Šturcova, A., Davies, G.R. and Eichhorn, S.J. (2005). Elastic modulus and stress-transfer properties of tunicate cellulose whiskers. Biomacromolecules 6, 1055-1061.

Sugiyama, J., Chanzy, H. and Maret, G. (1992). Orientation of cellulose microcrystals by strong magnetic fields. Macromolecules 25, 4232-4234. 
Tanaka, F. and Iwata, T. (2006). Estimation of the elastic modulus of cellulose crystal by molecular mechanics simulation. Cellulose 13, 509-517.

Tarchevsky, I.A. and Marchenko, G.N. (1991). Cellulose: Biosynthesis and structure (Springer, Berlin).

Tashiro, K., Kobayashi, M. and Tadokoro, H. (1977). Elastic moduli and molecular structures of several crystalline polymers, including aromatic polyamides. Macromolecules 10, 413-420.

Tashiro, K. and Kobayashi, M. (1985). Calculation of crystallite modulus of native cellulose. Polym. Bull. 14, 213-218.

Tashiro, K. and Kobayashi, M. (1991). Theoretical evaluation of three-dimensional elastic constants of native and regenerated celluloses: role of hydrogen bonds. Polymer 32, 1516-1526.

Taylor, I.E.P. and Wallace, J.C. (1989). The structural association between cellulose and xyloglucan in the primary cell wall of beans. In: Cellulose and wood: chemistry and technology. Proceedings of the Tenth Cellulose Conference, C. Schuerch, ed. (John Wiley and Sons, New York), pp. 273-282.

Tolstoguzov, V. (2004). Why are polysaccharides necessary? Food Hydrocolloids 18, 873-877.

Treloar, L.R.G. (1960). Calculations of elastic moduli of polymer crystals: III. Cellulose, Polymer 1 , 290-303.

Tze, W.T.Y., Gardner, D.J., Tripp, C.P. and O’Neill, S.C. (2006). Cellulose fiber/polymer adhesion: effects of fiber/matrix interfacial chemistry on the micromechanisms of the interphase. J. Adhes. Sci. Technol. 20, 1649-1668.

Tze, W.T.Y., O’Neill, S.C., Tripp, C.P., Gardner, D.J., and Shaler, S.M. (2007). Evaluation of load transfer in the cellulosic-fiber/polymer interphase using a micro-Raman tensile test. Wood Fiber Sci. 39, 184-195.

U.S. Department of Energy, Office of Science. Genomics: GTL Roadmap; Available online: http:// genomicsgtl.energy.gov/roadmap/ (accessed on August 12, 2012)

Valadez-Gonzalez, A., Cervantes-Uc, J.M., Olayo, R. and Herrera-Franco, P.J. (1999). Effect of fibre surface treatment on the fibre-matrix bond strength of natural fibre reinforced composites. Compos. B 30, 309-320.

Van Daele, Y., Revol, J.F., Gaill, F. and Goffinet, G. (1992). Characterization and supramolecular architecture of the cellulose-protein fibrils in the tunic of the sea peach (Halocynthia papillosa, Ascidiacea, Urochordata). Biol. Cell 76, 87-96.

Vietor, R.J., Mazeau, K., Lakin, M. and Perez, S. (2000). A priori crystal structure prediction of native cellulose. Biopolymers 54, 342-354.

Wada, M., Kondo, T. and Okano, T. (2003). Thermally induced crystal transformation from cellulose I $\alpha$ to Iß. Polym. J. 35, 155-159.

Wada, M., Heux, L. and Sugiyama, J. (2004). Polymorphism of cellulose I family: reinvestigation of cellulose IV . Biomacromolecules 5, 1385-1391.

Watanabe, A., Morita, S. and Ozaki, Y. (2007). Temperature-dependent changes in hydrogen bonds in cellulose l $\alpha$ studied by infrared spectroscopy in combination with perturbation-correlation moving-window two-dimensional correlation spectroscopy: Comparison with cellulose I $\beta$. Biomacromolecules 8, 2969-2975.

Wellard, H.J. (1954). Variation in the lattice spacing of cellulose. J. Polym. Sci. 13, 471-476.

Willstätter, R. and Zechmeister, L. (1913). Zur Kenntnis der Hydrolyse von Cellulose I. Ber. Deutsch. Chem.. Ges. 46, 2401-2412.

Witter, R.; Sternberg, U.; Hesse, S., Kondo, T., Koch, F-Th. and Ulrich, A.S. (2006). 13C chemical shift constrained crystal structure refinement of cellulose l $\alpha$ and its verification by NMR anisotropy experiments. Macromolecules 39, 6125-6132.

Woodcock, C. and Sarko, A. (1980). Packing analysis of carbohydrates and polysaccharides. 11. Molecular and crystal structure of native ramie cellulose. Macromolecules 13, 1183-1187.

Wool, R.P. and Sun, X.S. (2005). Bio-based polymers and composites (Elsevier, Amsterdam). 
Xu, W., Mulhern, P.J., Blackford, B.L., Jericho, M.H. and Templeton, I. (1994). A new atomic force microscopy technique for the measurement of the elastic properties of biological materials. Scanning Microsc. 8, 499-506.

Yeh, W.-Y. and Young, R.J. (1999). Molecular deformation processes in aromatic high modulus polymer fibres. Polymer 40, 857-870.

Yu, L.; Dean, K. and Li, L. (2006). Blends and composite from renewable resources. Prog. Polym. Sci. 31, 576-602.

Zugenmaier, P. (2001). Conformation and packing of various crystalline cellulose fibers. Prog. Polym. Sci. 26, 1341-1417. 